\title{
Los signos y el lenguaje sagrado de los 20 días en el calendario ritual de la Mixteca y los códices del noroeste de Oaxaca
}

\author{
Laura Rodríguez Cano
}

La reconstrucción de la lista de los 20 días del calendario ritual y sus nombres en mixteco ha sido posible a partir de los trabajos con los códices del área noroeste de Oaxaca emprendidos por Caso (1958), Jiménez Moreno (1962), Dahlgren (1952) y Smith (1973). Éstos han sido una verdadera clave para relacionar los logogramas, el numeral y el día con la palabra mixteca correspondiente. En este artículo presentamos cómo en el Mapa de Xochitepec, el Códice Mixteco Postcortesiano núm. 36 y el Mapa de San Vicente el Palmar, tres códices de la Mixteca Baja, se mencionan los nombres calendáricos de los señores cuyos registros de antropónimos no se conocían. Las glosas en lengua mixteca en estos documentos permiten corroborar los nombres de los días en mixteco en la mayoría de las posiciones, con ligeros cambios en sus grafías, y el uso de un lenguaje especial de los nombres mixtecos.

PALABRAS CLAVE: calendario, lengua mixteca, antropónimos, logogramas, Mixteca Baja

The Signs and the Sacred Language of the 20 Days in the Ritual Calendar of the Mixteca and the Codices of the Northeast of Oaxaca

The reconstruction of the list of the 20 days in the ritual calendar and their Mixtec names was made possible by the studies of the codices of the northeastern area of Oaxaca done by Caso (1958), Jiménez Moreno (1962), Dahlgren (1952), and Smith (1973). Their works have truly been the key for relating the logograms, the numerals, and the days to their corresponding Mixtec word. This paper shows how three codices from the Mixteca Baja - Mapa de Xochitepec, Códice Mixteco Postcortesiano no. 36, and the Mapa de San Vicente el Palmar - mention the calendrical names of the rulers, whose anthroponyms transcriptions were formerely unknown. The glosses in Mixtec in these documents allow us to corroborate the Mixtec names of the days in most positions, with slight variations in their graphic symbols, and the use of a special language for Mixtec names.

KEY WORDS: calendar, mixtec language, onomastic signs, Logograms, Mixteca Baja

LaURA Rodríguez CANO: Escuela Nacional de Antropología e Historia-Instituto Nacional de Antropología e Historia, México laurarcano@hotmail.com 


\section{INTRODUCCIÓN}

$\mathrm{E}$ xiste evidencia del uso de varios ciclos de tiempo en Mesoamérica, pero el más importante es el calendario ritual o el ciclo de 260 días, conformado por 20 nombres de días que se combinan con 13 numerales. Éste es uno de los cómputos de tiempo que sólo ocurre en Mesoamérica y del que se parte para realizar otras cuentas de tiempo ${ }^{1}$. El ciclo de 260 días se encuentra muy bien documentado tanto por la evidencia prehispánica desde el Preclásico hasta el Posclásico (500 a.C. a 1521 d.C.), como por los registros de los frailes en el periodo colonial ${ }^{2}$. Su carácter sagrado y adivinatorio era fundamental para la vida social, política y religiosa de estas culturas. Esta importancia queda manifiesta al comprobar que, mucho tiempo después de la conquista y hasta nuestros días, se siguió utilizando entre diversos grupos de Oaxaca y el área maya ${ }^{3}$.

Los estudios de Alfonso Caso con códices, crónicas y tradición oral notaron que, en este calendario, a pesar de ser compartido por toda Mesoamérica, los nombres que recide cultura en cultura, y que no siempre se tenía claro el registro de todos los nombres y su significado en determinadas posiciones de la lista. Caso también se percató de que sucede lo mismo con los diferentes logogramas ${ }^{4}$ utilizados en las inscripciones en piedra y en los códices para designar

\footnotetext{
${ }^{1}$ Es decir, que los mismos signos y numerales del calendario de 260 días distribuidos y contados de diferentes maneras llevan a cálculos sobre el ciclo de 52 años, el de 584 días, entre otros, tal y como están registrados en los diversos códices calendárico-religiosos llamados tonalamatl (cf. Códice Borbónico, Códice Borgia, Códice Vaticano B).

${ }^{2}$ Véanse inscripciones en piedra que datan desde 500 a.C. y también los registros de cronistas como Sahagún (2000) en el centro de México; Landa (1986) en el área maya; Alvarado (1962), Reyes (1953) y Córdova (1987) en Oaxaca, zonas mixteca y zapoteca.

${ }^{3}$ Cf. Alcina (1993), quien encuentra en el Archivo General de Indias, en Sevilla, España, unos librillos del siglo XVII en los que los zapotecas de la sierra todavía llevaban la cuenta de los días. O véanse también las etnografías de Weitlaner hacia el noroeste de Oaxaca; en la zona mixteca véase Hermann (2003), así como los estudios de Tedlock (1993) para el área maya.

${ }^{4}$ Dentro de un sistema de escritura antiguo se entiende por logograma cualquier signo o glifo que corresponde a una palabra de la lengua (cf. Gelb, 1987). En este caso, los signos o glifos de los días del calendario ritual se consideran parte del sistema de escritura mixteco y, como tal, logogramas, ya que representan una palabra de la lengua mixteca.
}

cada uno de los 20 días de la lista del calendario ritual ${ }^{5}$. Desde entonces se han propuesto diferentes reconstrucciones, de acuerdo con la cultura en la que se originan, para los logogramas de los 20 nombres de los días. Para ello se han utilizado distintas claves provenientes de fuentes coloniales o la comparación de estilos de una misma época ${ }^{6}$, y se ha podido comprobar que cada cultura tiene una forma particular de representar y de nombrar a cada día. Éstos pueden presentar variantes en sus formas glíficas y en sus glosas en caracteres alfabéticos en lengua indígena. Una posible explicación de estas variaciones puede radicar en su relación con el aspecto simbólico que los escribanos nativos de cada cultura buscan destacar ${ }^{7}$.

Como parte de los estudios sobre nuevas evidencias y propuestas de reconstrucción de los 20 días, este artículo tiene, como uno de sus objetivos centrales, presentar la lista de los nombres mixtecos de los días del ciclo ritual registrados en el Mapa de San Vicente el Palmar de la región de la Mixteca Baja ${ }^{8}$, comparados con otros códices de esa misma región (Becker II, Tulane, Egerton o Sánchez Solís, Mixteco Postcortesiano núm. 36 y Mapa de Xochitepec $)^{9}$, que también conservan nombres mixtecos y logo-

${ }^{5}$ Cf. Caso, 1967.

${ }^{6} \mathrm{Al}$ respecto, véanse por ejemplo, para los días mexicas, principalmente a Sahagún (2000) y los códices religiosos del centro de México, como el Borbónico y el Telleriano Remensis, entre otros; para los días mayas principalmente Landa (1986), Thompson (1950) y la tradición oral; para el caso zapoteco véase Urcid (1992), donde se resumen otras propuestas de reconstrucción para los días zapotecos anteriores a la de este autor. Para otras culturas prehispánicas mesoamericanas véanse Caso (1967) y Edmonson (1995). Para el caso ñuiñe a Rodríguez (1996, 1999); para el de Xochicalco a Rodríguez (2005), y para el mixteco a Caso (1956), Smith (1973a) y Hermann (2003), entre otros.

${ }^{7}$ Para algunos ejemplos, véase Rodríguez, 2001.

${ }^{8}$ Este mapa colonial con escritura indígena tradicional ya había sido reportado por Smith y Parmenter (1991), pero hasta ahora no se conocía el contenido de sus glosas y logogramas. Su análisis durante 2005 a 2007 ha mostrado que su contenido no registra al pueblo de San Vicente el Palmar, pero en este artículo nos seguiremos refiriendo a este documento como Mapa de San Vicente el Palmar, por haberse encontrado en este pueblo y conservando también la denominación que le dio Smith en 1991.

${ }^{9}$ Algunos de los documentos citados no han sido publicados, o bien, las fotografías publicadas no son adecuadas para trabajarlos (cf. Smith, 1973a; y Caso, 1958), por lo que para su estudio tuvimos acceso a los siguientes ejemplares: en el caso del Mapa de San Vicente el Palmar se recurrió a la la copia de un lienzo del siglo XVI, Lienzo 57 glosas, en el Archivo del Registro Agrario Nacional de Oaxaca, así como a las fotografías del mapa original tomadas en San Vicente durante el trabajo 
gramas que permitieron a diferentes estudiosos obtener las claves para reconstruir la lista de los 20 días del calendario ritual de la Mixteca.

Desde un punto de vista epigráfico el artículo pone énfasis en la estructura y las reglas que siguen los registros de logogramas y glosas. Con tal fin se explicará la estructura logográfica que tienen los signos del calendario de 260 días registrados en los códices históricos prehispánicos, y se compararán los logogramas de los 20 días y las variantes que se emplean para representarlos. Después se revisarán los estudios sobre estos aspectos de Jiménez Moreno e Higuera (1940) con el Códice Sierra, de Dahlgren (1990 [1954]) y Caso (1967) con el Lienzo de Nativitas, y de Smith (1979) con el Egerton o Sánchez Solís y el Mixteco Postcortesiano núm. 36, quienes logran identificar, en un lenguaje especial, los nombres mixtecos de los 20 días del calendario ritual empleado en esa región, así como los logogramas correspondientes. Se analizarán las evidencias encontradas en cada uno de estos códices, considerando también al Códice Sierra y el Nativitas ${ }^{10}$, de la región mixteca-chocholteca, debido a que fueron claves importantes en el proceso de reconstrucción de la lista de los días mixtecos ${ }^{11}$. Finalmente, se presentarán los registros de los nombres de los días escritos en el Mapa de San Vicente el Palmar.

de campo del proyecto "Geografía-histórica de la Mixteca Baja: toponimia y espacio políticos del siglo VIII al XVI", a cargo de Laura RodrígueZ Cano en la Escuela Nacional de Antropología e Historia (ENAH), México, 2004-2005; y al registro gráfico escala 1:1 del Mapa de San Vicente el Palmar del proyecto "Geografía-histórica de la Mixteca Baja: Toponimia y espacio políticos del siglo VIII al XVI" antes citado, 2007. En cuanto al Códice Mixteco Postcortesiano núm. 36, se consultó la fotografía a tamaño natural en el Museo Regional de Huajuapan de León, Oaxaca, s. f., y el registro gráfico 1:1 obtenido por el proyecto citado. Para el Mapa de Xochitepec se consultaron las fotografías del Museo Nacional de Copenhague, Dinamarca, proporcionadas por Michel Oudijk en 2001, y la copia de este códice que se encuentra en la Mapoteca de la Subdirección de Documentación de la Biblioteca Nacional de Antropología e Historia, así como a su registro gráfico 1:1 obtenido en el mismo proyecto.

${ }^{10}$ Para el análisis de los glifos y glosas del Lienzo de Nativitas se recurrió a la fotografía facsímil donada por la Biblioteca Burgoa a Santa María Nativitas, a las fotografías del original tomadas en agosto de $2005 \mathrm{du}-$ rante un trabajo de campo del proyecto de investigación formativa "Cosmovisión, escritura e imagen de Meosamérica", coordinado por Laura Rodríguez Cano en la ENAH, México, 2005; y al registro gráfico 1:1 realizado durante el trabajo de campo en agosto 2005 del mismo proyecto. ${ }^{11}$ No se toman en cuenta otros códices coloniales de la Mixteca Alta que pudieran tener registros de nombres calendáricos para esta compara-
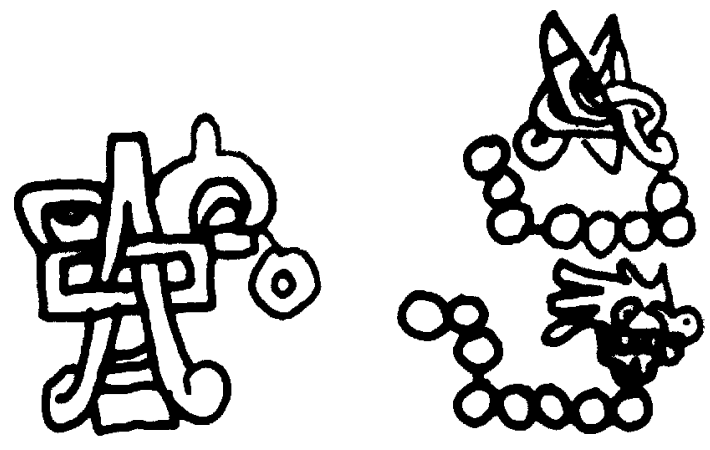

Figura 1. Convención para registrar fechas. Fuente: Códice Bodley y Códice Nuttall.

\section{LOS SIGNOS DE LOS DÍAS MIXTECOS}

Debido a la evidencia en códices prehispánicos y coloniales elaborados por los mixtecos, así como en fuentes realizadas por cronistas europeos, sean éstos oficiales reales o religiosos dominicos ${ }^{12}$, se sabe que los mixtecos usaban un calendario de 260 días conformado por trece numerales en un sistema de puntos cuyos coeficientes iban del 1 al 13 y veinte signos de días. Al igual que otros grupos mesoamericanos, lo utilizaron durante el Posclásico, última etapa antes de la conquista, en la que se hicieron los códices prehispánicos que hoy se conocen. Dicho calendario se empleó para especificar fechas dentro de un ciclo de 52 años ${ }^{13}$, o bien, para formar antropónimos o nom-

ción, primero, porque nuestra área de estudio es la Mixteca Baja y, segundo, porque el análisis de los 20 nombres de los días se centra en la evidencia que proporciona esta región. Sólo se incluyeron dos códices de la zona mixteco-chocholteca debido a que fueron la clave o "Piedra de Rosetta" que permitió dar paso a la reconstrucción de la lista de los 20 días mixtecos. Se debe señalar, sin embargo, que el Códice Muro de la Mixteca Alta, entre sus registros de glosas mixtecas de fechas y nombres personales, tiene 19 nombres mixtecos de la lista y 17 logogramas de los 20 días. Entre los nombres mixtecos encontrados hay una variante para el día Agua (tucha/tuncha) y para el día Perro (yuhua/na). $\mathrm{Al}$ respecto, véase Hermann, 2003.

${ }^{12}$ Cf. los códices Vindoboensis, Nuttall, Bodley, Selden, Colombino y Becker, de origen prehispánico, o bien el Yanhuitlán, el Lienzo de Coixtlahuaca, el Dehesa o el Lienzo de Zacatepec, entre otros, elaborados durante la Colonia por diferentes motivos; o bien, véase a Gregorio García (1981) o las Relaciones Geográficas del siglo XVI (Acuña, 1984 y 1985). ${ }^{13}$ El ciclo de 52 años también es concido como "siglo indígena", "rueda calendárica" o "xiuhmolpilli". Al cierre de este ciclo se conmemo- 


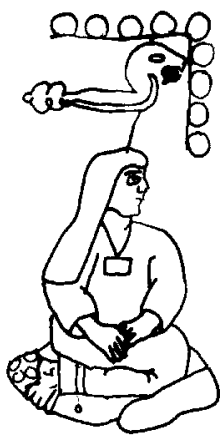

Figura 2. Convención para registrar nombres calendáricos. Fuente: Códice Tulane.

bres calendáricos de personas. La escritura mixteca registra como convención principal para denotar este calendario la siguiente asociación regular (figs. 1 [p. 35] y 2):

Signo día + Numeral de puntos del 1 al 13

Estos logogramas, relacionados por cercanía espacial o con lazos gráficos a personajes, indicarían que funcionan como nombres calendáricos de esas personas. En cambio, si estos logogramas aparecen por cercanía o con un lazo gráfico a una fecha anual entonces su función es la de indicar la fecha de un día.

Otra posibilidad del esquema anterior sería que este logograma de día y numeral se asociara con un glifo del año; en ese caso su función sería la de una fecha anual, quedando el siguiente patrón regular:

Signo día + Numeral de puntos del 1 al 13 + Glifo del año

Si se hace una rápida revisión de los códices prehispánicos de esta región para obtener de ellos la lista de los 20 signos de los días mixtecos ${ }^{14}$ encontramos que en los que pertenecen a la Mixteca Alta y de la Costa (Vindobonensis o Viena, Bodley, Nuttall, Selden, Colombino, Becker I) y de los coloniales de la Mixteca Baja (Becker II y Tulane) aparecen, en distintos momentos de la narración de su historia, registros de los 20 signos representados por los logogramas indicados por los siguientes glifos (véase también tabla 1, pp. 38-41):

- Lagarto: representado por el ojo y la mandíbula superior de este animal, ocupa la primera posición de la secuencia de los 20 días.

- Viento: el logograma de la segunda posición es la máscara bucal del dios del Viento, que a veces puede llevar también la barba y el gorro cónico.

- Casa: en la tercera posición, aparece como una construcción con techo curvo o plano.

- Lagartija: es la cuarta posición en la secuencia y su ícono es este reptil, ya sea de cuerpo entero, destacando la cabeza, las patas y la cola, o bien sólo la cabeza. En algunos ejemplos parece más iguana, por su piel escamosa y puntiaguda (fig. 3 ).

- Serpiente: en la quinta posición, este ofidio puede representarse sólo por su cabeza con lengua bífida y colmillos o bien de cuerpo entero.

- Muerte: es la sexta posición; se representa con un cráneo humano de perfil.

- Venado: la séptima posición es la cabeza de este animal y, por lo general, se marca su cornamenta.

- Conejo: es la octava posición; su logograma es la cabeza de este pequeño mamífero, en la que destacan las orejas largas y sus dos incisivos; en algunos casos aparecen líneas negras indicando su pelaje.

- Agua: es la novena posición de la lista y su logograma es una corriente acuática; puede aparecer en sus terminaciones con caracoles y conchitas.

- Perro: es la décima posición y se representa por medio de la cabeza de este cánido; resaltan la lengua de fuera y los colmillos.

de mixteco durante el año 2003. Las reconstrucciones de cada lista de los 20 signos de días en cada códice fue realizada por Rosalba Sánchez, Itzel González, Ernesto Granados y Tania Gopar. raba una atadura de años y se hacía una ceremonia en honor al fuego nuevo entre los mexicas. Está conformado por trece numerales y cuatro signos de días, los cuales aparecen espaciados cada cinco posiciones de la lista de los 20 días del ciclo ritual (cf. Rodríguez, 2001).

${ }^{14}$ Esta revisión fue emprendida por los alumnos de la materia optativa 


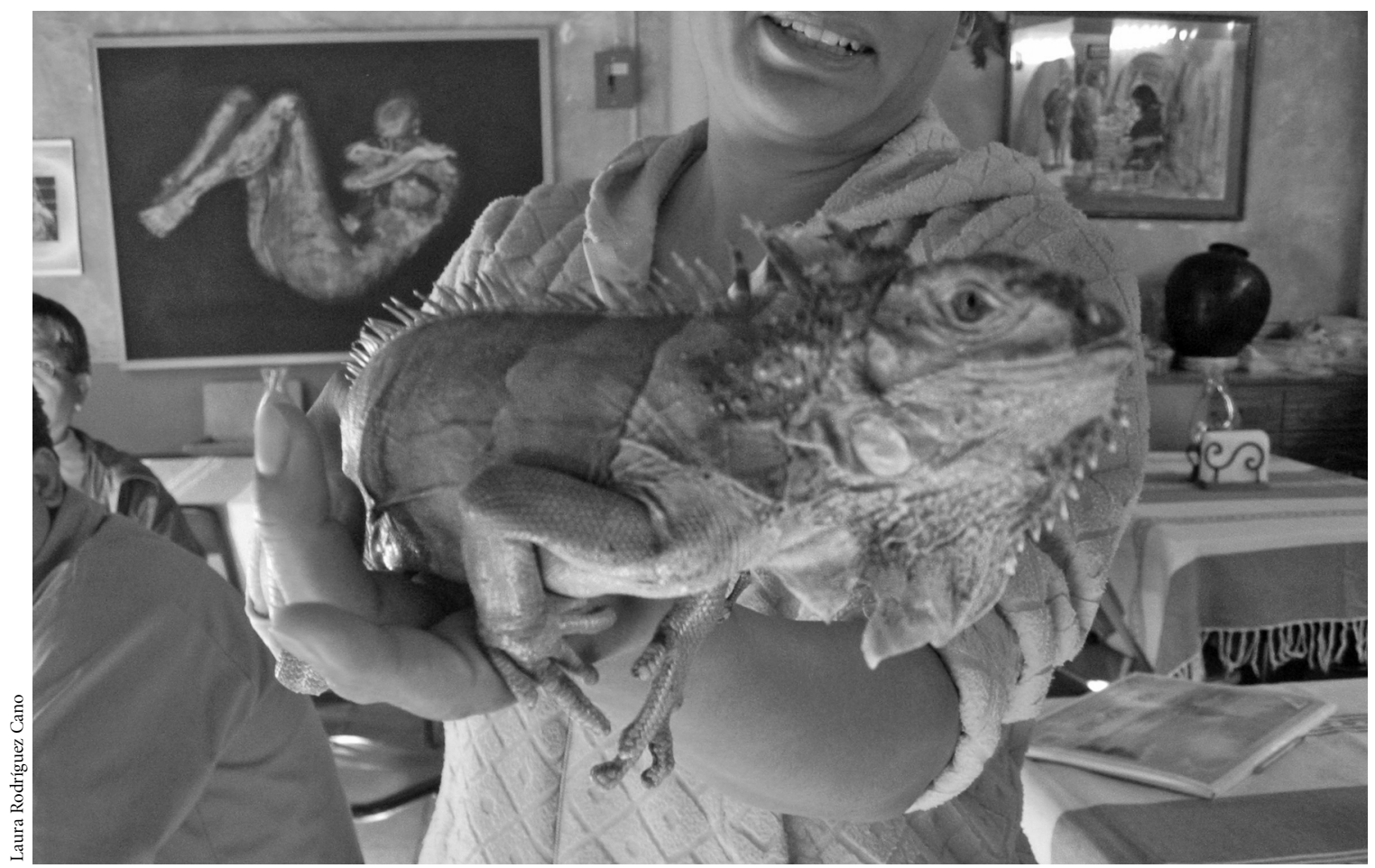

Figura 3. Iguana. Restaurante Bugambilias, Huajuapan de León, Oaxaca, enero de 2007.

- Mono: es la décimoprimera posición y su logograma es la cabeza de este animal, en la que destacan una orejera como adorno y un copete en la parte superior de la cabeza.

- Hierba: décimosegunda posición; está representada por una mandíbula humana descarnada con plantas y otros atributos de la deidad 9 Hierba.

- Caña: el logograma de la décimotercera posición son los carrizos utilizados como astas para la elaboración de las flechas o lanzas.

- Jaguar: en décimocuarta posición; se representa con la cabeza con manchas negras de este felino.

- Águila: el logograma de la décimoquinta posición se indica, por lo general, con la cabeza de esta ave, aunque existen ejemplos de cuerpo entero. Una característica son sus plumas separadas en el contorno de la cabeza.

- Zopilote: la décimosexta posición se representa con la cabeza de este pájaro; una de sus características es el pico alargado y la cabeza lisa o con plumas muy juntas.
- Temblor: el logograma de la décimoséptima posición es la representación de la tierra y su movimiento por medio de un esquema del espacio mesoamericano con los cuatro rumbos y el centro.

- Pedernal: es la décimooctava posición y se indica por un cuchillo de piedra de silex en colores rojo y blanco.

- Lluvia: el logograma de la décimonovena posición lleva los atributos de la deidad de la lluvia, anteojera, bigotera y largos colmillos.

- Flor: representa la vigésima posición con un elemento vegetal con tres volutas en forma de pétalos.

En dos códices de la Mixteca de la Costa (el Colombino y el Becker I), que son fragmentos de uno más completo, al haber sido dañados intencionalmente muchos de sus signos calendáricos están borrados ${ }^{15}$, por lo que en

${ }^{15}$ Cf. Estudio en el Códice Alfonso Caso, 1995. 
Tabla 1. Comparativo de los logogramas de los 20 días en algunos códices prehispánicos

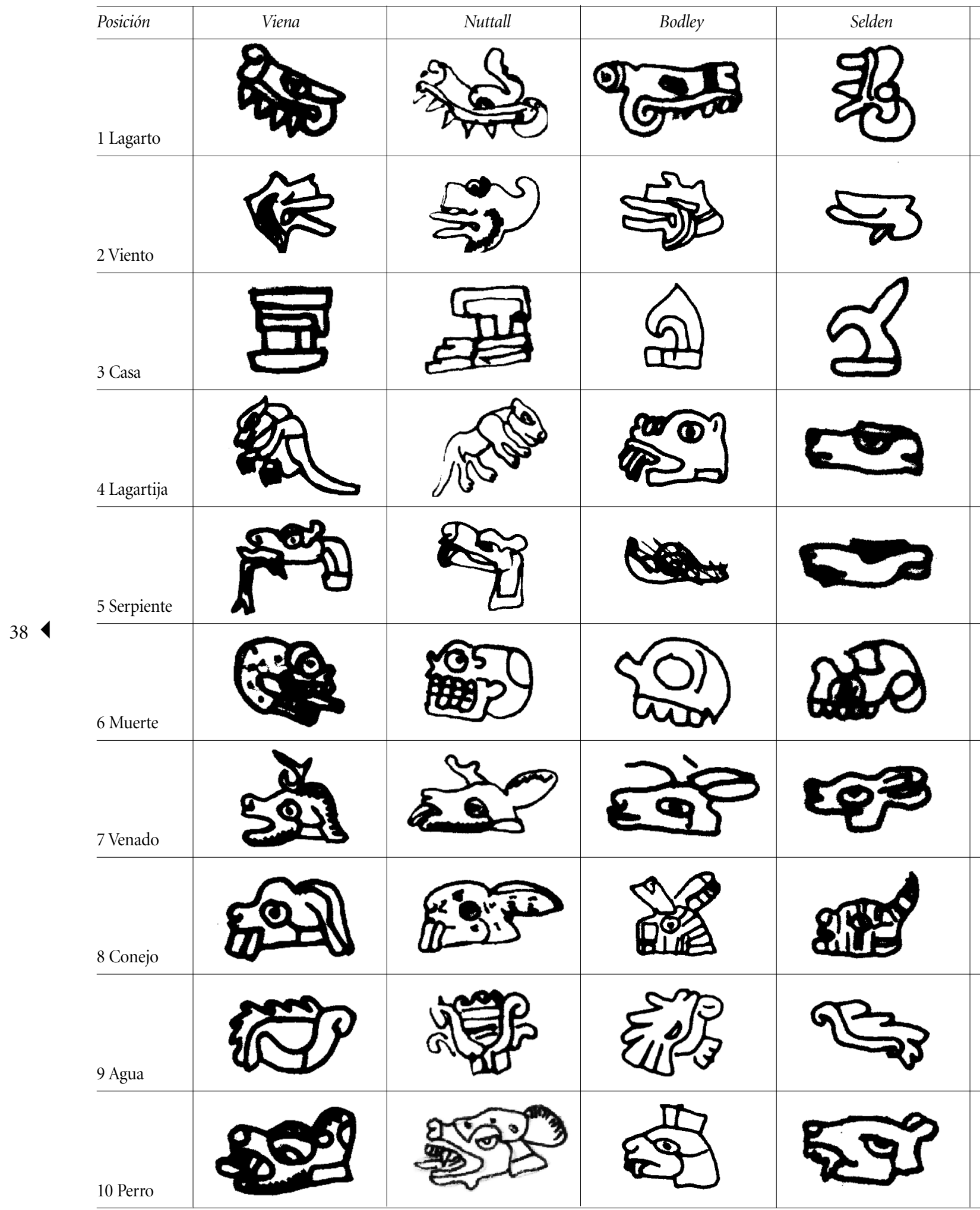


y coloniales en el que no se presentan asociadas las glosas en lengua mixteca

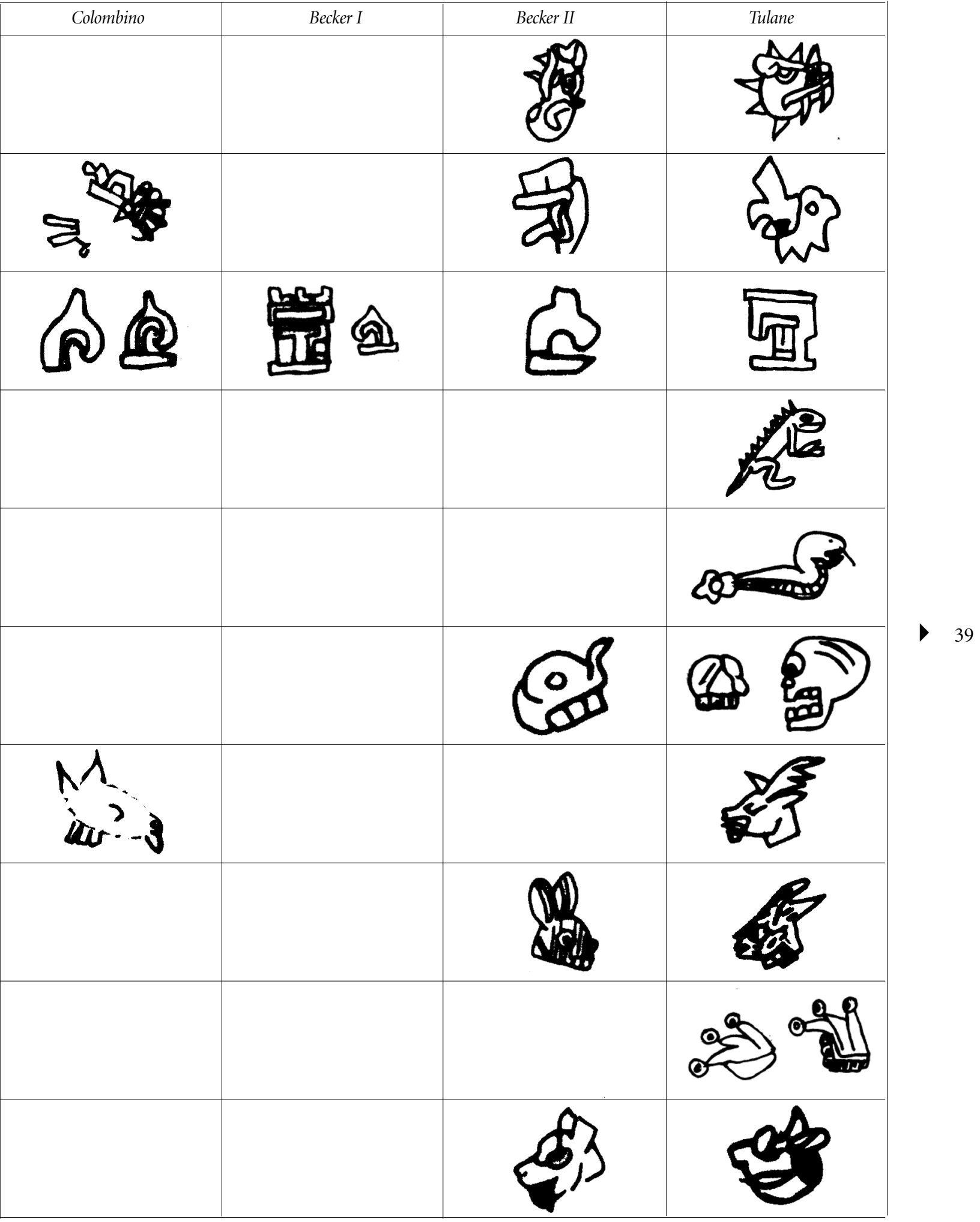




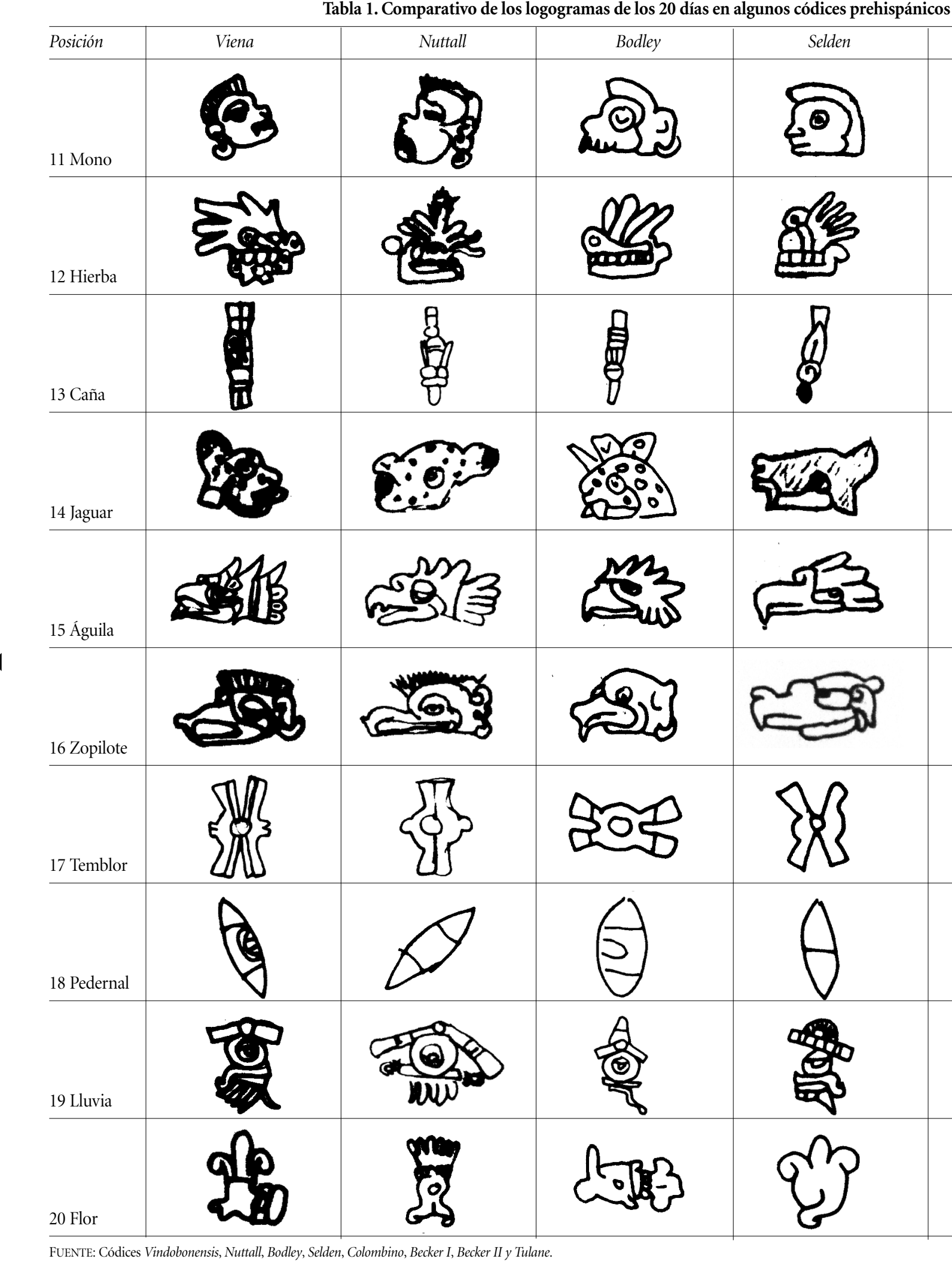


y coloniales en el que no se presentan asociadas las glosas en lengua mixteca (continuación)

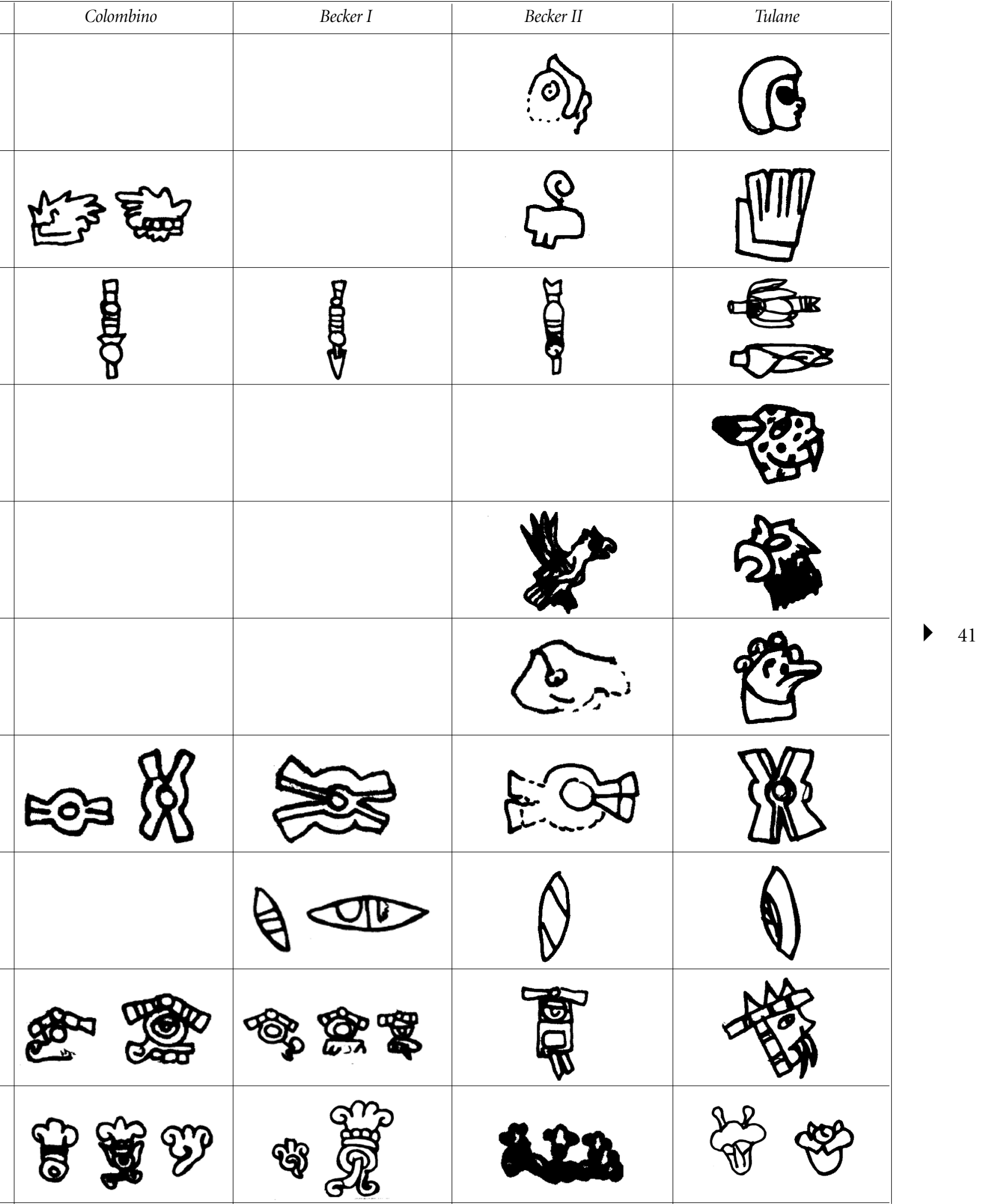


la sección de los 20 días del Colombino sólo se conservan nueve signos (Viento, Casa, Venado, Hierba, Caña, Movimiento, Pedernal, Lluvia y Flor), y en la del Becker I, únicamente seis días (Casa, Caña, Movimiento, Pedernal, Lluvia y Flor) (tabla 1, pp. 38-41).

A esta comparación también se le ha decidido agregar dos códices (Becker II y Tulane), ya coloniales, que provienen de la Mixteca Baja ${ }^{16}$, y cuyos días no están asociados con glosas. El primero, por ser un fragmento, sólo tiene registrados quince de los veinte signos (Lagarto, Viento, Casa, Muerte, Conejo, Perro, Mono, Hierba, Caña, Águila, Zopilote, Movimiento, Pedernal, Lluvia y Flor), pero el segundo conserva los 20 logogramas de los días (tabla 1, pp. 38-41).

Esta revisión de los signos-días mixtecos en los códices de las tres regiones de la Mixteca permite notar, además de las diferencias de caligrafías en las representaciones de los logogramas — que pueden remitir a escuelas tal vez regionales ${ }^{17}$ - varios principios de la escritura mixteca, como son: la rotación (que permite consignar los signos en forma horizontal o vertical, tal como ocurre en sión (que se refiere a que los signos pueden estar pintados hacia la derecha o hacia la izquierda, como en los días $1^{\mathrm{a}}, 2^{\mathrm{a}}, 3^{\mathrm{a}}, 4^{\mathrm{a}}, 5^{\mathrm{a}}, 6^{\mathrm{a}}, 7^{\mathrm{a}}, 8^{\mathrm{a}}, 9^{\mathrm{o}}, 11^{\mathrm{a}}, 12^{\mathrm{a}}, 14^{\mathrm{a}}, 15^{\mathrm{a}}, 16^{\mathrm{a}}$ y $\left.19^{\mathrm{a}}\right)$, y el uso de la parte por el todo (que permite representar signos con el animal u objeto completo, o bien, sólo una parte de él, como se ve en las posiciones $2^{\mathrm{a}}, 4^{\mathrm{a}}, 5^{\mathrm{a}}, 15^{\mathrm{a}} \mathrm{y}$ $20^{\mathrm{a}}$ ). En cada uno de los documentos pueden aparecer indistintamente rotaciones, inversiones o pars pro toto, por ejemplo, en el códice Nuttall.

Los códices anteriores muestran la forma que tenían los logogramas de los días mixtecos, pero no permiten conocer cuáles eran las palabras mixtecas que les correspondían. En el caso de otras regiones de Mesoamérica, la manera de reconstruir la lista de los 20 signos de los días ha

16 Cf. Smith, 1979; y Smith y Parmenter, 1991.

${ }_{17}$ Para la definición de escuelas regionales, cf. Robertson (1959), quien fue el primero en proponer la existencia de éstas en los códices (tlatelolcas, mexicas y texcocanos) de la cuenca de México. Recientemente, Brito (2006) ha considerado los documentos de Huexotzingo como representantes de una escuela diferente del centro de México, pero la idea no se ha seguido trabajando para el resto de Mesoamérica.

sido apoyándose, como herramienta central, en los vocabularios, artes y crónicas que escribieron los frailes ${ }^{18}$. Sin embargo, para los días mixtecos no ha resultado igual, ya que si comparamos los nombres comunes que da el vocabulario de la lengua mixteca de fray Antonio de Alvarado con los nombres especiales o sagrados que se han propuesto para los días mixtecos, se observa que, en general, no concuerdan. Sólo en cuatro días que da el vocabulario parecería que el final de las palabras tiene alguna relación con el nombre sagrado del día mixteco del calendario. Por ejemplo, en el día de la segunda posición, Viento, que en el lenguaje común es tachi y en el especial chi. Otro caso es el de la novena posición, Agua, que en el lenguaje común se dice nduta y en el especial o sagrado se registra como tuta. Lo mismo sucede para la décimosexta posición, Zopilote, que en el lenguaje común es tisii y en el especial se refiere como cuii. Curiosamente, una entrada que da Alvarado para Conejo, día de la octava posición, es sacuaa, y parte de esa palabra se usa como nombre sagrado en el día calendárico de la séptima posición: Venado - cuaa ${ }^{19}$ (tabla 2).

Estas diferencias llevan a pensar, como propusieron hace ya algunos años Arana y Swadesh (1961), con base en el Arte de la lengua mixteca de fray Antonio de los Reyes (1953), en un lenguaje de los señores $(y y a)^{20}$ en el cual se

${ }^{18}$ Cf., para el caso zapoteco, Urcid (1992, 2001); para el maya véase Landa (1986), y para el centro de México la obra de Sahagún $(1979,2000)$. ${ }^{19}$ Es interesante anotar la observación de Hermann (2003: 81) en la que dice que algunos de los nombres especiales o sagrados de los días mixtecos se pueden encontrar en el vocabulario de Alvarado, como el caso de la palabra para lagarto, venado y hierba, respectivamente quevui, 'día o tiempo'; cuaa, 'amarillo', y cuañe, 'suelo áspero', cuyo significado aparentemente dista mucho de su representación logográfica. Sin embargo, atendiendo al primer ejemplo comentado por Hermann (2003), es muy probable pensar que, para los mixtecos, aunque el logograma fuera un lagarto, su nombre en mixteco resaltaba el significado de tiempo, es decir, se está destacando en ese nombre que con el día lagarto se inicia la cuenta del calendario y el del tiempo, tal y como reporta para el centro de México la Historia de los mexicanos por sus pinturas (2003). Estos casos muestran cómo aún falta mucho trabajo por hacer para entender las relaciones que existen entre los 20 nombres de los días, su logograma y su significado.

${ }^{20}$ Cf. Arana y Swadesh, 1961. Después Jansen (1985), propone el concepto de lenguas divinas, un lenguaje utilizado por las élites mesoamericanas (mayas, nahuas, mixtecas, etc.), basado en metáforas, difrasismos, palabras honoríficas y especiales. Los mixtecos usaron este lenguaje principalmente en el calendario. 
adscribiría también el calendario de 260 días, por su carácter sagrado. Ese lenguaje especial y respetuoso, muy posiblemente, al dejarse de usar con la conquista y durante la Colonia, pervivió en palabras arcaicas, como ocurre con el término para iguana en la región de Jamiltepec ${ }^{21}$, o bien quizás pasó a formar parte del lenguaje común, recopilado por el diccionario de Alvarado en el siglo XVI, pero ya no con el mismo sentido que tuviera antes.

\section{ANTECEDENTES DE LOS NOMBRES MIXTECOS DE LOS DÍAS}

Puesto que los diccionarios en lengua mixteca no resultan útiles, aparentemente, para conocer este lenguaje especial, los distintos estudiosos ${ }^{22}$ que han propuesto reconstrucciones para la lista de los 20 signos de los días mixtecos lo han hecho a partir de la interpretación de un corpus de códices del noroeste de la Mixteca que se ha conservado ${ }^{23}$. Wigberto Jiménez Moreno, en la década de 1940, es el primero que se percata de que el Códice Sierra —editado por Nicolás León a principios del siglo XX一, que es un libro de cuentas del pueblo de Texupan con glosas en lengua náhuatl y con signos de escritura tradicional nahua y mixteca, como el glifo del año, tiene, entre su texto en náhuatl, frases en lengua mixteca que registran la manera de decir los años en esa lengua. Después, Barbro Dahlgren, en su trabajo de campo en la Mixteca, conoce el Lienzo de Santa María Nativitas y paleografía las glosas mixtecas asociadas con los signos calendáricos de los personajes. Ella es la primera en proponer, con base en la evidencia arrojada por ese códice y la del Sierra, 17 nombres en lengua mixteca con sus variantes para los 20 días del calendario de 260 días mixteco. Más adelante, Alfonso Caso retoma esta información y, con los datos del Mapa de Xochitepec, las Relaciones Geográficas del

${ }^{21}$ Comentario personal de Julieta León, 2003, recopilado en su trabajo de campo en Jamiltepec para su tesis de licenciatura en la ENAH (León Romero, 2004).

${ }^{22}$ Cf. Jiménez, 1940; Dahlgren, 1990 [1954]; Caso, 1967; Smith, 1973a, 1973 b.

${ }^{23}$ Códice Sierra, Lienzo de Santa María Nativitas, Códice Egerton, Códice Mixteco Postcortesiano núm. 36 y Mapa de Xochitepec.
Tabla 2. Lista de los 20 días del calendario de 260 según el vocabulario del siglo XVI de Alvarado comparada con la propuesta de reconstrucción de la lista de los días mixtecos

\begin{tabular}{|c|c|c|c|}
\hline Posición & $\begin{array}{c}\text { Nombres } \\
\text { en español } \\
\text { Alvarado, } 1593\end{array}$ & $\begin{array}{l}\text { Nombre } \\
\text { común }\end{array}$ & $\begin{array}{c}\text { Nombre } \\
\text { especial } \\
\text { Smith, } 1973 a\end{array}$ \\
\hline 1 & Lagarto & cooyechi & Queui \\
\hline 2 & Viento & tachi & Chi \\
\hline 3 & Casa & huahi & Mao Cuao \\
\hline 4 & Lagartija & tiyechi & $\mathrm{Qu}(\mathrm{e})$ \\
\hline 5 & Serpiente & $\mathrm{COO}$ & Yo \\
\hline 6 & Muerte & sihi & Mahu(a) \\
\hline 7 & Venado & idzo & Cuaa \\
\hline 8 & Conejo & idzo sacuaa & Sayu \\
\hline 9 & Agua & nduta & Tuta \\
\hline 10 & Perro & ina & Hua \\
\hline 11 & Mono & codzo & Nuu \\
\hline 12 & Hierba & yucu & Cuañe \\
\hline 13 & Caña & ndoo & Huiyo \\
\hline 14 & Jaguar & cuiñe & Huidzo \\
\hline 15 & Águila & yaha & $\mathrm{Sa}$ \\
\hline 16 & Zopilote & tisii & Cuii \\
\hline 17 & Temblor & tnaa nehe & Qhi \\
\hline 18 & Pedernal & yuchi & Cusi \\
\hline 19 & Lluvia & dzauui & Co \\
\hline 20 & Flor & ita & Huaco \\
\hline
\end{tabular}

Se resaltan en negrita algunas coincidencias en las palabras de ambas columnas. Fuente: Smith, 1973a.

siglo XVI y el Vocabulario de Alvarado, reconstruye los nombres faltantes para los tres días que aún no se conocían. Su propuesta de reconstrucción, no obstante, no resulta muy convincente debido a la falta de evidencia para la asociación de los glifos con una glosa en lengua mixteca. Finalmente, Mary Elizabeth Smith, retomando lo realizado por Jiménez, Dahlgren y Caso e incorporando la información de sus estudios sobre el Códice Mixteco Postcortesiano núm. 36 y, en especial, la de su trabajo sobre los 
antropónimos en el Códice Egerton, en el que analiza la relación existente entre la glosa y su asociación con los glifos, encuentra también los tres nombres de días que faltaban, dando otras variantes en el lenguaje especial a las propuestas por Caso de acuerdo con Alvarado y recuperando sólo el nombre en el lenguaje común (tabla 3).

\section{CÓDICES MIXTECOS SEMEJANTES A LA PIEDRA DE ROSETTA}

Este pequeño corpus de códices del noroeste de Oaxaca, en especial el Códice Sierra, el Lienzo de Santa María Nativitas, el Códice Egerton y el Códice Mixteco Postcortesiano núm. $36^{24}$, resultó una importante clave ${ }^{25}$ para conocer los nombres sagrados o especiales de los días mixtecos debido a que en todos ellos aparecen fechas o personajes cuyos antropónimos son glifos calendáricos $y$, asociados con ellos, se encuentran las glosas en caracteres alfabéticos en lengua mixteca. Estas glosas, al igual mada por tres partes. Si atendemos a que el mixteco es una lengua cuyas palabras se forman con monosílabos o bisílabos, entonces la primera palabra hace referencia al año (cuyya-) o al día (qui-), si se trata de fechas, o bien a un título de respeto o una forma reverencial para los señores o señoras (yya-, ya-, ñu-, yyaciy, yaciy-) si se trata de un antropónimo. La sílaba siguiente hace referencia al numeral (1-ca/co, 2-cu/co/ca, 3-co, 4-qhi, 5-q, 6- $\tilde{n} u, 7-s a$, 8-na, 9-que, 10-si, 11-si, 12-ca, 13-si) ${ }^{26}$, y la última parte

\footnotetext{
24 Para conocer más sobre el contenido, las medidas, el soporte y la localización de estos códices, remitirse a Glass, 1975, y a estudios especializados como los de Smith, 1973a y 1973b; Köning, 1979; León, 1982; y Van Doesburg, 2001, entre otros.

${ }^{25}$ Como lo fue la Piedra de Rosetta para la escritura egipcia, de ahí la comparación que hago de estos códices con esta inscripción egipcia. ${ }^{26}$ Los numerales también se hallan en un lenguaje especial, porque son parte importante del calendario de 260 días, pero por cuestiones de espacio no se tratarán aquí (cf. Smith, 1973a y Rodríguez, en preparación). Se puede observar que algunos números se escribieron con las mismas grafías, tal vez sus diferencias se deben a los tonos de la lengua mixteca que en la época colonial no fueron registrados regularmente por los glosistas de los códices, ya que, al parecer, en el Códice Muro sí se trató de hacer una distinción (cf. Hermann, 2003). Estas irregulari-
}

de la glosa denota el nombre del día en el calendario de 260 días $^{27}$. Resultan entonces los siguientes esquemas:

a) Fechas de años:

Palabra para año + palabra para un numeral del 1 al 13 + nombre del día.

b) Fechas de días:

Palabra para día + palabra para un numeral del 1 al $13+$ nombre del día.

c) Nombres calendáricos de personas:

Palabra honorífica + palabra para un numeral del 1 al $13+$ nombre del día.

Si atendemos a esta estructura morfológica de las glosas se puede entonces analizar la evidencia de estos códices, lo que permite entender todas las variaciones que existen en cada uno de los documentos del corpus y, así, acercarnos a identificar las glosas mixtecas calendáricas de los antropónimos del Mapa de San Vicente el Palmar, que hasta ahora no se conocían ${ }^{28}$. Estos registros hacen que este mapa pase a formar parte del corpus de documentos que proporciona evidencias para conocer los nombres mixtecos de los 20 días.

dades en el registro de la lengua mixteca durante la Colonia hacen que la transcripción sea problemática y provocan cambios de letras en las palabras mixtecas (problema que veremos con detenimiento en los nombres de los días), ya que se utilizaron grafías del alfabeto latino para representar los sonidos de la lengua mixteca que no reflejan fielmente los fonemas de este idioma. Testimonio de esta dificultad son los esfuerzos que ha emprendido la Academia de la Lengua Mixteca para establecer otros signos que representen algunos de los sonidos de la lengua mixteca que las grafías del alfabeto latino no proporcionan (cf. Caballero, 2007: 256).

${ }^{27}$ No se incluyen aquí los nombres de los 20 días, ya que se abundará en ellos en el resto del artículo.

${ }^{28}$ El Mapa de San Vicente el Palmar es mencionado en el catálogo de códices de la Mixteca Baja que aparece en el apéndice al estudio introductorio del Códice Tulane, hecho por Smith y Parmenter en 1991, y hasta esa fecha no existía un estudio publicado sobre este documento, por lo que, dentro de la investigación realizada en el marco del proyecto "Geografía histórica de la Mixteca Baja: Toponimia y espacio político del siglo VIII al XVI" de la ENAH, fue registrado gráfica y fotográficamente durante el trabajo de campo realizado en 2004-2005, lo que permitió conocer las glosas de los antropónimos presentados en este artículo. 
Tabla 3. Antecedentes de reconstrucciones de los nombres de la lista de los 20 días del calendario mixteco según Dahlgren (1990 [1954]), Caso (1967) y Smith (1973a) en comparación con el diccionario de Alvarado e indicando la posición de la lista

\begin{tabular}{|c|c|c|c|c|c|c|}
\hline \multirow[t]{2}{*}{ Posición } & \multirow[t]{2}{*}{ Dahlgren, 1954} & \multicolumn{2}{|c|}{ Caso, 1967} & \multicolumn{2}{|c|}{ Smith, 1973a } & \multirow[t]{2}{*}{ Alvarado, 1593} \\
\hline & & mixteco & español & mixteco & español & \\
\hline 1 & queui & Quehui & ¿día? & Queui & Lagarto & cooyechi \\
\hline 2 & chi & Chi & Viento & Chi & Viento & tachi \\
\hline 3 & Mau/cuau & $\begin{array}{l}\text { Cuau } \\
\text { Mao } \\
\text { huahi }\end{array}$ & $\begin{array}{l}\text { Casa } \\
\text { Cuao }\end{array}$ & Mao & Caso & huahi \\
\hline 4 & $q$ & Cuu & ¿? & $\mathrm{Qu}(\mathrm{e})$ & Lagartija & tiyechi \\
\hline 5 & yo & $\begin{array}{l}\text { Yucoco } \\
\text { Serpiente } \\
\text { yo }\end{array}$ & & yo & Serpiente & $\mathrm{COO}$ \\
\hline 6 & mahua & Mahua & Muerte & Mahu(a) & Muerte & sihi \\
\hline 7 & Cuaa & Cuaa & Venado & Cuaa & Venado & idzo \\
\hline 8 & Sayu & Xayu & Conejo & Sayu & Conejo & Idzo sacuaa \\
\hline 9 & i? & Duta & Agua & Tuta & Agua & nduta \\
\hline 10 & va & $\mathrm{Ua}$ & Coyote & Hua & Perro & ina \\
\hline 11 & ñuu & Nuu & ¿? & Ñuu & Mono & codzo \\
\hline 12 & cuañe & Cuañe & Hierba & Cuañe & Hierba & yucu \\
\hline 13 & uiyo & Huiyo & Caña & Huiyo & Caña & ndoo \\
\hline 14 & vidzo & Vidzo & Gato montés & Huidzo & Jaguar & cuiñe \\
\hline 15 & ¿? & Хауасu & Águila & $\mathrm{Sa}$ & Águila & yaha \\
\hline 16 & cuii & Cuij & Pavo & Cuii & Zopilote & tisii \\
\hline 17 & qhi & Qhi & ¿? & Qhi & Temblor & Tnaa nehe \\
\hline 18 & uisi & Cuxi & Pedernal & Cusi & Pedernal & yuchi \\
\hline 19 & i? & Dzahui & Lluvia & Co & Lluvia & dzauui \\
\hline 20 & vaco & Uaco & Flor & Huaco & Flor & ita \\
\hline
\end{tabular}

La evidencia del Códice Sierra (fig. 4, p. 46)

Este códice, de 62 láminas, tiene registros de cuentas del pueblo de Texupan desde 1550 a 1564. En tan sólo 14 de sus láminas aparece la glosa mixteca que relaciona al logograma anual —-formado por el glifo del año, el numeral y el signo de día que da nombre al año-. En este documento sólo se emplean cuatro signos de días, uno distinto para nombrar cada año; al quinto se vuelve a repetir el nombre del año con el que se inició la serie, aunque los coeficientes cambian dentro de un ciclo de 52. Este códice, por lo tanto, sólo registra cuatro signos con sus respectivos nombres mixtecos, que conforman los portadores de año en el ciclo de 52 años y que aparecen con las posiciones 13a-18a-3a-8a: Caña, Pedernal, Casa, Conejo (huiyo, cuxi, mao, xayu, respectivamente) ${ }^{29}$. La tabla 4 (p. 47)

${ }^{29}$ Siguiendo la convención empleada por Alfonso La Cadena, en el cur- 


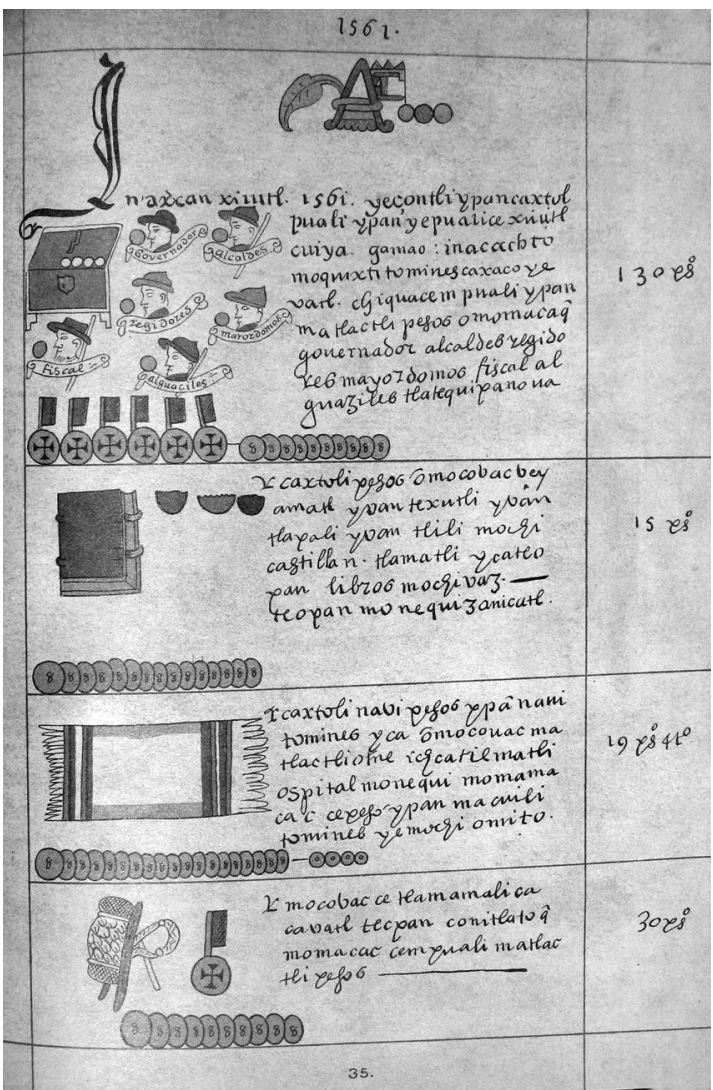

Figura 4. Lámina 35 del Códice Sierra, tomada de León (1982), en la que se observa el logograma 3 Casa y la glosa cuiya gamao (traducción: 'año 3 casa')

muestra el análisis realizado a estas glosas ${ }^{30}$. Se puede notar que en la lámina 47 no existe correspondencia entre el registro del logograma que es Año 3 Casa y la glosa mixteca del segundo renglón que dice cuyya $+c o+c u x i$ (Año+12+Pedernal). Otro dato que resulta del análisis

so impartido en la Universidad Nacioanl Autónoma de México (UNAM) sobre escritura mexica en mayo de 2005, se utilizan mayúsculas para indicar la transcripción de un logograma y minúsculas para indicar la transcripción de una glosa. También se debe señalar que se usan signos de + para el análisis morfológico de las glosas.

${ }^{30}$ Este análisis de las 14 láminas del Códice Sierra se hizo dentro de la materia optativa de Etnohistoria de la Mixteca en el año 2003 y colaboraron en él Itzel González, Rosalba Sánchez, Ernesto Granados, Tania Gopar y Julieta León.

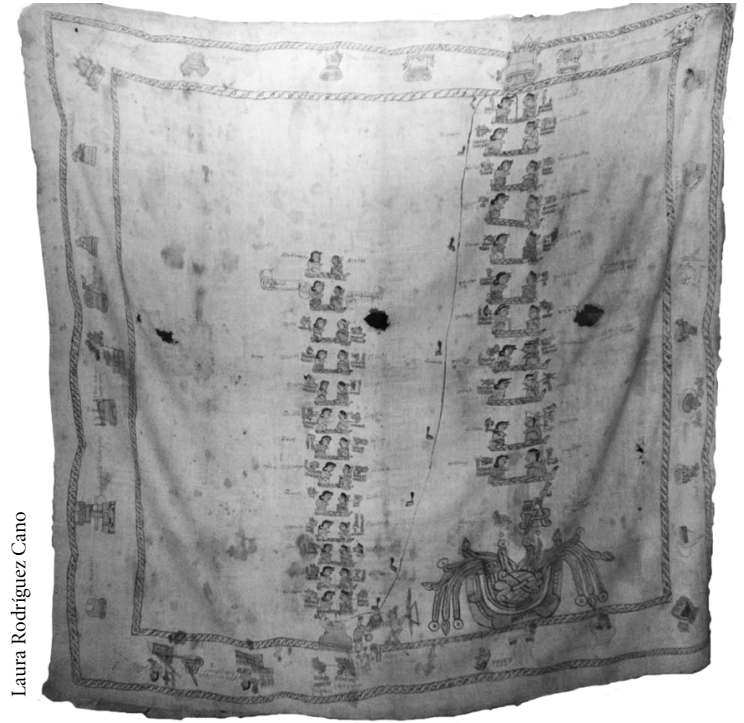

Figura 5. Lienzo de Santa María Nativitas. Temporada de campo del proyecto de investigación formativa "Cosmovisión, escritura e imagen en Mesoamerica” de la ENAH, agosto de 2005.

efectuado es la variación del nombre mixteco para Casa que, curiosamente, ocurre cuando no hay presencia de su logograma y cuando las glosas dan alternativas de quao, qqao (L19 y L48 respectivamente). Es sabido que estos nombres corresponden al día Casa por la secuencia que llevan los nombres de los años dentro del ciclo de 52 años (tabla 4).

\section{La evidencia del Lienzo de Santa María Nativitas} (fig. 5)

Este lienzo histórico-cartográfico del siglo XVI ${ }^{31}$, como su clasificación lo indica, contiene una sección histórica central conformada por dos fechas anuales que son fundacionales. La primera: Año 1 Caña - el día 1 Lagarto (cui $+c a+v i y o-q u i+c o+q u e v i)$, muestra el origen de una genealogía de parejas gobernantes de Nativitas, representadas sobre un petate. Cada una de ellas cuenta con el regis-

\footnotetext{
${ }^{31}$ Cf. Caso, 1992 [1977].
} 
Tabla 4. Información calendárica sobre los días mixtecos del Códice Sierra

\begin{tabular}{|c|c|c|c|c|}
\hline Lámina & $a \tilde{n} o$ & Glifo & glosa & Análisis \\
\hline $\mathrm{L} 2 / \mathrm{R} 3$ & 1551 & AÑO 6 CAÑA & cuyya nuhuiyo & cuyya+nu+huiyo \\
\hline L5/R3 & 1552 & AÑO 7 PEDERNAL & cuyya xacuxi & cuyya+xa+cuxi \\
\hline L8/R3 & 1553 & AÑO 8 CASA & cuyya namao & cuyya + na + mao \\
\hline${ }^{*} \mathrm{~L} 11 / \mathrm{R} 2$ & 1554 & AÑO 9 CONEJO & cuyya quexayu & cuyya+que+xayu \\
\hline L15/R2 & 1555 & AÑO 10 CAÑA & cuyya xihuiyo & cuyya+xi+huiyo \\
\hline L19/R9 & 1556 & No hay & cuyya xicuxi & $\begin{array}{l}\text { cuyya+xi+cuxi } \\
(\text { año }+11+\text { pedernal })\end{array}$ \\
\hline${ }^{\star} \mathrm{L} 19 / \mathrm{R} 12$ & 1557 & No hay & cuyya caquao & $\begin{array}{l}\text { cuyya+ca+quao } \\
(\text { año }+12+\text { casa })\end{array}$ \\
\hline L24/R3 & 1559 & AÑO 1 CAÑA & cuyya gauhuiyo & cuyya+gau+huiyo \\
\hline${ }^{*} \mathrm{~L} 29 / \mathrm{R} 2$ & 1560 & AÑO 2 PEDERNAL & cuyya cocuxi & cuyya + co + cuxi \\
\hline${ }^{*} \mathrm{~L} 35 / \mathrm{R} 3$ & 1561 & AÑO 3 CASA & cuyya gamao & cuyya+ga+mao \\
\hline L47/R2 & 1561 & AÑO 3 CASA & cuyya cocuxi & $\begin{array}{l}\text { cuyya }+ \text { co }+ \text { cuxi } \\
(\text { año }+12+\text { pedernal })\end{array}$ \\
\hline L48/R5 & 1561 & No hay & cuyya caqqao & $\begin{array}{l}\text { cuyya+caq+gao } \\
(\text { año }+12+\text { casa })\end{array}$ \\
\hline L49/R4 & 1562 & AÑO 4 CONEJO & cuyya [roto] & cuyya $+i ?+[$ recons-trucción:xayu $]$ \\
\hline${ }^{\star} \mathrm{L} 55 / \mathrm{R} 5$ & 1563 & AÑO 5 CAÑA & cuyya q.huiyo & cuyya $+q+$ huiyo \\
\hline L61/R6 & 1564 & AÑO 6 PEDERNAL & cuyya ñucuxi & cuyya $+\tilde{n} u+$ cuxi \\
\hline
\end{tabular}

Datos tomados del Códice Sierra, de Jiménez (1940); los asteriscos son datos también de Dahlgren (1990 [1954]). Se señalan en negritas los nombres mixtecos encontrados.

tro de su antropónimo, tanto en glifos como en glosas. En esta sección también se anota la existencia de una guerra, a partir de la cual el linaje se divide, provocando la fundación de la segunda genealogía en la fecha Año 5 Conejo - el día 9 Lagarto (cuiya $+q+$ sayu - qui+quevi). Esta segunda genealogía también cuenta con sus antropónimos en los dos tipos de escritura ${ }^{32}$.

\footnotetext{
32 Agradecemos a las autoridades del pueblo de Santa María Nativitas su disponibilidad y hospitalidad para realizar el registro gráfico y fotográfico de este códice, que no hubiera sido posible sin las gestiones realizadas por Eric García durante su servicio social. En este registro, llevado a cabo entre mayo y agosto de 2005, participaron Itzel González, Rosalba Sánchez, Eric García, Alejandro Díaz, Carmen Silva, Paulina Ortega y Dulce Hernández, alumnos y ex alumnos del proyecto de investigación formativa "Cosmovisión, escritura e imagen", del que soy responsable en la ENAH.
}

Tabla 5: Análisis de fechas fundacionales del Lienzo de Santa María Nativitas

\begin{tabular}{c|c|c}
\hline Glifos & Glosas & Análisis \\
\hline AÑO 1 CAÑA & cuicaviyo & Cui+ca+viyo \\
\hline 1 LAGARTO & quicoquevi & Qui+co+quevi \\
\hline AÑO 5 CONEJO & cuiyaqsayu & Cuiya+q+sayu \\
\hline 9 LAGARTO & quiquevi & Qui+quevi \\
\hline
\end{tabular}

Se señalan en negritas los nombres mixtecos encontrados.

Del análisis de las tablas 5, 6 (p. 48) y 7 (p. 49) se concluye que en este códice existen 31 registros de nombres calendáricos, tomando en cuenta fechas y antropónimos, de los cuales 17 son registros diferentes que representan 17 nombres mixtecos de la lista de los 20 días en las posi- 
Tabla 6. Análisis de los glifos y glosas de la primera genealogía del Lienzo de Santa María Nativitas

\begin{tabular}{|c|c|c|c|c|c|c|c|}
\hline Logograma & $\begin{array}{l}\text { Glifo } \\
\text { mujer }\end{array}$ & $\begin{array}{l}\text { Glosa } \\
\text { mujer }\end{array}$ & Análisis & Logograma & $\begin{array}{c}\text { Glifo } \\
\text { hombre }\end{array}$ & $\begin{array}{l}\text { Glosa } \\
\text { hombre }\end{array}$ & Análisis \\
\hline $\begin{array}{l}8 \% \text { wos } \\
80000 \\
00000\end{array}$ & 13 CONEJO & yasisayu & Ya+si+sayu & 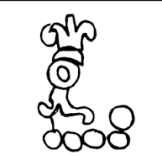 & 5 FLOR & yaqvaco & Ya+q+vaco \\
\hline$\frac{10}{20}$ & $3 \mathrm{MONO}$ & yacoñuu & $Y a+c o+\tilde{n} u \mathbf{u}$ & 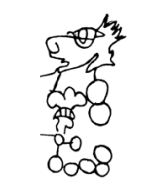 & $\begin{array}{l}2 \text { PERRO } \\
5 \text { FLOR }\end{array}$ & yacaua & $\begin{array}{c}\begin{array}{c}\text { Ya+ca+va } \\
(\text { nombre }\end{array} \\
5 \text { FLOR } \\
\text { no tiene } \\
\text { glosa) }\end{array}$ \\
\hline 8 & 10 TEMBLOR & yasiqhi & $\mathrm{Ya}+\mathrm{si}+\mathbf{q h i}$ & $\frac{50}{8}$ & 5 TEMBLOR & yaqqhi & $\mathrm{Ya}+\mathrm{q}+\mathbf{q h i}$ \\
\hline $\begin{array}{l}898 \\
800000 \\
80000\end{array}$ & 13 LAGARTO & yasiq'vi & $\mathrm{Ya}+\mathrm{si}+$ quevi & $\begin{array}{l}\text { Fेj } \\
60000 \\
00000\end{array}$ & 10 CONEJO & yasisayu & $\mathrm{Ya}+\mathrm{si}+\mathbf{s a y u}$ \\
\hline $\begin{array}{l}8 \sqrt{05} \\
8 v a 5 \\
00000 \\
00000\end{array}$ & $13 \mathrm{MONO}$ & yasiñuu & Ya+si+ñuu & $\begin{array}{l}\text { af का } \\
\text { ode } \\
\text { bo }\end{array}$ & 3 LAGARTO & yacoq'ui & $\mathrm{Ya}+\mathrm{co}+$ quevi \\
\hline $\begin{array}{c}\text { 尚 } \\
00000 \\
00000\end{array}$ & 10 FLOR & yñusivaco & Yñu+si+vaco & & $1 \mathrm{CASA}$ & yacomau & $\mathrm{Ya}+\mathrm{co}+\mathbf{m a u}$ \\
\hline$\sum_{0000}^{203}$ & 8 TEMBLOR & ñunaqhi & $\tilde{\mathrm{Nu}}+\mathrm{na}+\mathbf{q h i}$ & 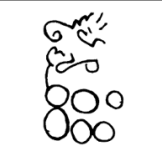 & 6 PERRO & ñusava & $\tilde{\mathrm{Nu}}+\mathrm{sa}+\mathbf{v a}$ \\
\hline$c$ & 2 ZOPILOTE & ñucocu & $\tilde{\mathrm{Nu}}+\mathrm{co}+\mathrm{cu}$ & $\begin{array}{l}\text { के } \\
0000 \\
0000\end{array}$ & 9 MUERTE & ñuq'cauhu & $\tilde{\mathrm{Nu}}+q u e+\mathrm{cauhu}$ \\
\hline 皮 & 6 VENADO & ñuñucuaa & $\tilde{\mathrm{Nu}}+\tilde{\mathrm{n} u}+\mathrm{cuaa}$ & $\begin{array}{l}\text { क्षेत } \\
0000 \\
0000\end{array}$ & 8 MUERTE & ñunumahu & $\overline{\mathrm{Nu}}+\mathrm{un}+\mathrm{mahu}$ \\
\hline $\begin{array}{l}\text { and } \\
00000 \\
00000\end{array}$ & 10 ZOPILOTE & ñusicuii & $\tilde{\mathrm{Nu}}+\mathrm{si}+\mathrm{cuii}$ & $\begin{array}{l}\text { 包8 } \\
\text { क00 } \\
00000\end{array}$ & 13 MUERTE & ñusimahu & $\tilde{\mathrm{Nu}}+\mathrm{si}+\mathrm{mahu}$ \\
\hline Oobo & 4 PEDERNAL & ñuquisi & $\begin{array}{c}\tilde{N} u+q u i s i \\
\tilde{N} u+q+u i s i\end{array}$ & $\begin{array}{c}8 \\
8 \\
0000 \\
00000\end{array}$ & 12 CAÑA & ñucaviyo & $\tilde{\mathrm{Nu}}+\mathrm{ca}+$ viyo \\
\hline
\end{tabular}


Tabla 7. Análisis de los glifos y glosas de la segunda genealogía del Lienzo de Santa María Nativitas

\begin{tabular}{|c|c|c|c|c|c|c|c|}
\hline Logograma & $\begin{array}{l}\text { Glifo } \\
\text { mujer }\end{array}$ & $\begin{array}{l}\text { Glosa } \\
\text { mujer }\end{array}$ & Análisis & Logograma & $\begin{array}{c}\text { Glifo } \\
\text { hombre }\end{array}$ & $\begin{array}{c}\text { Glosa } \\
\text { hombre }\end{array}$ & Análisis \\
\hline & & & & $\begin{array}{r}\text { :n } \\
\begin{array}{r}88 \\
88\end{array}\end{array}$ & 12 CAÑA & ñucacuañe & $\tilde{\mathrm{Nu}}+\mathrm{ca}+$ cuañe \\
\hline 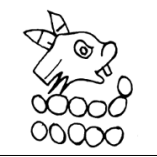 & 11 JAGUAR & ñusividzu & $\tilde{N u}+s i+v i d z u$ & & 8 ZOPILOTE & ñunacuii & $\tilde{\mathrm{Nu}}+\mathrm{na}+\mathrm{cuii}$ \\
\hline $\begin{array}{l}0 \% 00 \\
0,1000 \\
00000\end{array}$ & 12 JAGUAR & ñucavidzu & $\tilde{\mathrm{Nu}}+\mathrm{ca}+\mathbf{v i d z u}$ & G⿺ & 8 FLOR & ñunauaco & $\tilde{\mathrm{Nu}}+$ na + uaco \\
\hline क्ष & 8 SERPIENTE & ñunayo & $\tilde{\mathrm{Nu}}+\mathrm{na}+\mathbf{y o}$ & & $1 \mathrm{MONO}$ & ñucoñuu & $\tilde{\mathrm{Nu}}+\mathrm{co}+\tilde{\mathbf{n u u}}$ \\
\hline $\begin{array}{l}\angle 000 \\
000 \\
0\end{array}$ & 7 JAGUAR & ñusavidzu & $\tilde{\mathrm{Nu}}+\mathrm{sa}+$ vidzu & $\begin{array}{r}88 \\
8 \\
8 \\
8 \\
00 \infty \\
0\end{array}$ & 12 CAÑA & ñucauiyo & 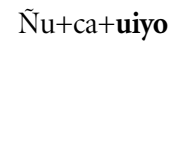 \\
\hline & 3 ZOPILOTE & ñucocuii & $\tilde{\mathrm{Nu}}+\mathrm{co}+\mathrm{cuii}$ & & 6 LAGARTIJA & ñuñuq & $\tilde{N u}+\tilde{n} u+q$ \\
\hline 85 & 13 CONEJO & ñusisayu & $\tilde{\mathrm{Nu}}+\operatorname{si}+\mathbf{s a y u}$ & $\begin{array}{l}\text { कृ0 } \\
80000 \\
00000\end{array}$ & 12 SERPIENTE & ñucayo & $\tilde{\mathrm{Nu}}+\mathrm{ca}+$ yo \\
\hline $\begin{array}{l}\text { क्षि } \\
88 \\
88\end{array}$ & 8 LAGARTIJA & ñunaq & $\tilde{\mathrm{Nu}}+\mathrm{na}+\mathbf{q}$ & $\begin{array}{l}\text { ong } \\
0000 \\
00000\end{array}$ & 10 SERPIENTE & ñusiyo & $\tilde{\mathrm{Nu}}+\mathrm{si}+$ yo \\
\hline $\begin{array}{l}8 \% \\
845 \\
60000 \\
000\end{array}$ & 13 VIENTO & ñusichi & $\tilde{\mathrm{Nu}}+\mathrm{si}+\mathrm{chi}$ & 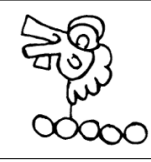 & 5 VIENTO & ñuqchi & $\tilde{\mathrm{Nu}}+\mathrm{q}+\mathrm{chi}$ \\
\hline$\frac{N^{2} y}{00000}$ & 11 VENADO & ñusiquaa & $\tilde{\mathrm{Nu}}+\mathrm{si}+$ quaa & $\begin{array}{l}\text { wa } 8 \\
\text { जits } 8 \\
0000\end{array}$ & 9 TEMBLOR & ñuq'qhi & $\tilde{\mathrm{Nu}}+q u e+q h i$ \\
\hline $\begin{array}{l}29 \\
0 \\
50\end{array}$ & 10 CASA & ñusicuau & $\tilde{\mathrm{Nu}}+\mathrm{si}+\mathrm{cuau}$ & $\begin{array}{l}508 \\
00000 \\
00000\end{array}$ & 13 VIENTO & ñusichi & $\tilde{\mathrm{Nu}}+\mathrm{si}+\mathrm{chi}$ \\
\hline 8 & 7 VIENTO & ñusachi & $\tilde{\mathrm{Nu}}+\mathrm{sa}+\mathrm{chi}$ & $\begin{array}{l}5^{8} 8 \\
00000 \\
00000\end{array}$ & 11 JAGUAR & ñus... & $\tilde{\mathrm{Nu}}+\mathrm{s}[\mathrm{iidzu}]$ \\
\hline
\end{tabular}




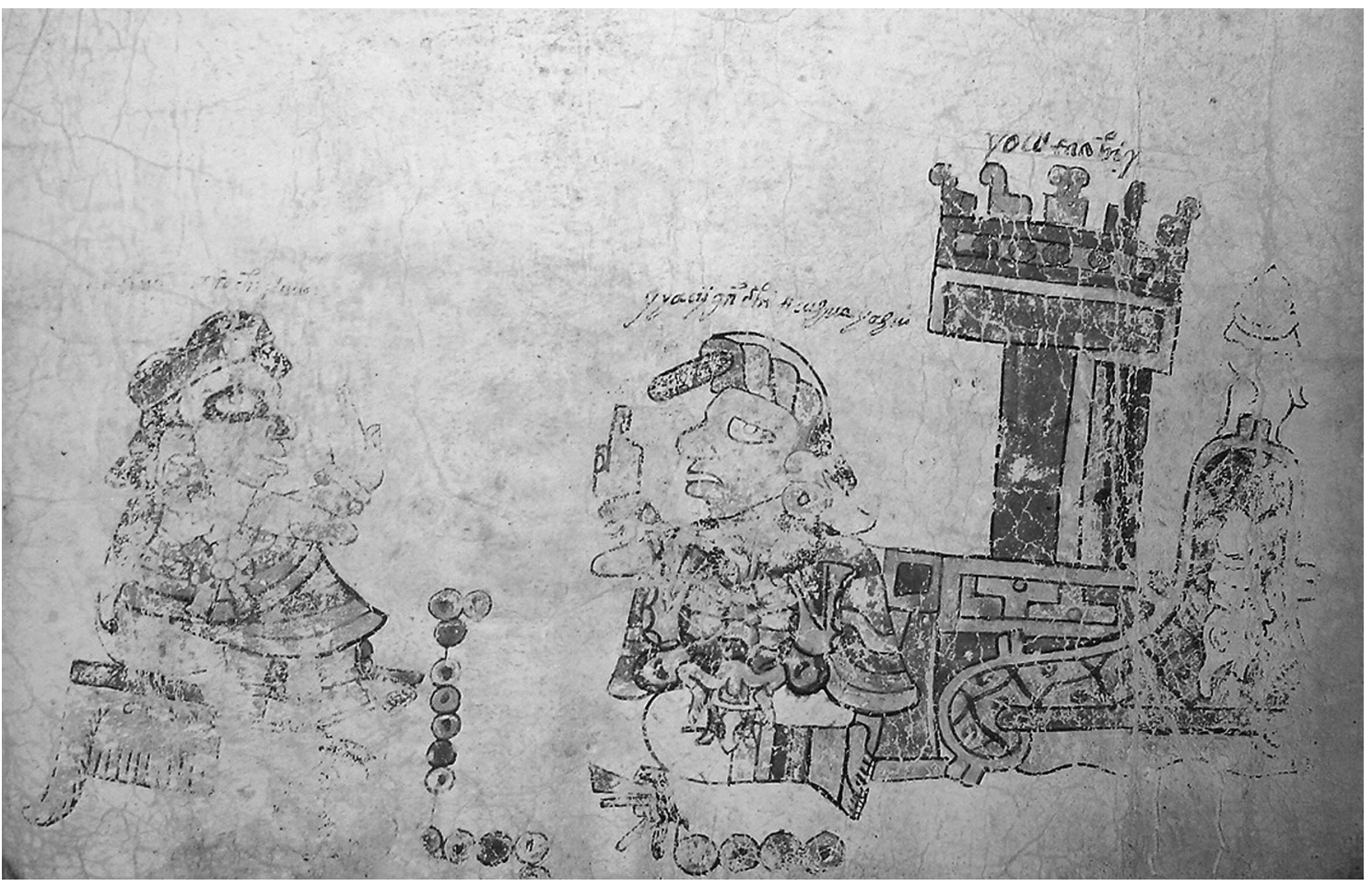

Figura 6. Lámina 22 del Códice Egerton o Sánchez Solís que muestra los logogramas y glosas calendáricas de los antropónimos de la pareja de señores. Tomada de Anders et al., 1994.

ciones: $1^{\mathrm{a}}$ (Lagarto), $2^{\mathrm{a}}$ (Viento), $3^{\mathrm{a}}$ (Casa), $4^{\mathrm{a}}$ (Lagartija), $5^{\mathrm{a}}$ (Serpiente), $6^{\mathrm{a}}$ (Muerte), 7a (Venado), $8^{\mathrm{a}}$ (Conejo), 10

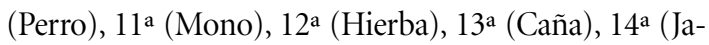
guar), 16a (Zopilote), 17a (Temblor), 18 ${ }^{\mathrm{a}}$ (Pedernal) y 20a (Flor). Además, podemos señalar que se registra una variante en el nombre del día Muerte (cauhu o mahu) y que se confirma la variante del nombre mixteco para el día Casa registrada en el Códice Sierra (cuau). En comparación con dicho códice, podemos ver que las grafías para los nombres de Casa, Conejo, Caña y Pedernal varían pero no lo alteran; las formas siguen siendo las mismas (tablas 5, 6 y 7 , pp. 47, 48 y 49).

\section{La evidencia del Códice Egerton (fig. 6)}

Este códice mixteco colonial narra el origen y la historia de las alianzas de los linajes gobernantes de la Mixteca
Baja. A pesar de su deterioro, aún es posible ver los registros de glosas de topónimos y antropónimos en caracteres alfabéticos mixtecos y también los glifos del códice ${ }^{33}$. En sus 31 láminas existen 119 registros calendáricos, incluyendo glifos con glosas y sin ellas. Sabemos que existieron cinco de estos registros por la estructura del documento, pero ya no se distinguen, por lo que sólo quedan 114 todavía visibles que pueden ser identificados. De éstos, 45 son representaciones glíficas que aparentemente no están asociadas con glosas - muy probablemente las glosas se han perdido por el deterioro del códice- El resto, es decir, 69 registros, son glifos asociados con glosas que pueden verse en parte, tanto unos como otras.

Estas últimas evidencias funcionaron como clave para conocer los nombres especiales o sagrados de los días mix-

\footnotetext{
${ }^{33}$ Cf. Köning, 1979; Anders et al., 1994
} 


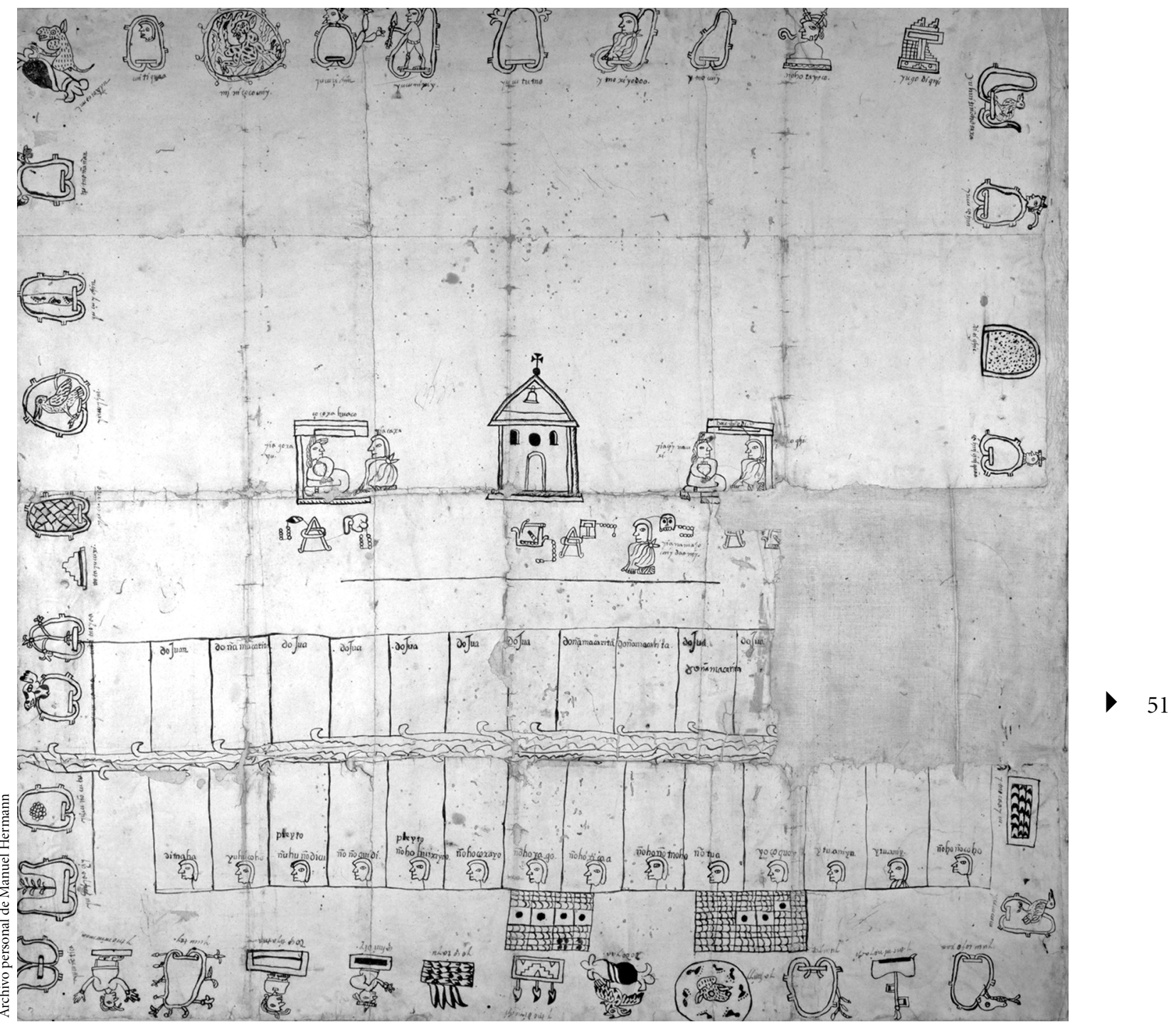

Figura 7. Códice Mixteco Postcortesiano núm. 36, Museo Nacional de Antropología e Historia.

tecos. Con base en la paleografía de las glosas presentadas en el estudio más reciente de este códice ${ }^{34} \mathrm{y}$ en la identificación epigráfica propia se pudo reconocer cada uno de estos registros y encontrar 20 glifos diferentes, que conforman el total de la lista de los 20 días del calendario de

${ }^{34}$ Cf. Anders et al., 1994.
260 días de la Mixteca Baja, aunque sólo 18 de estos glifos tienen su nombre correspondiente en lengua mixteca, pues faltan los datos en caracteres alfabéticos en mixteco para los días Muerte y Hierba (tabla 8, pp. 52-56).

Tras el análisis de la tabla 8 se puede señalar que existe en este códice una variante para el nombre del día Lagarto (qui) y otra para el día Mono (ño o ñoo), que no habían sido registradas en los otros dos códices analizados. 
Tabla 8. Glifos y glosas calendáricas de los antropónimos del Códice Egerton

\begin{tabular}{|c|c|c|c|c|c|c|c|}
\hline Logograma & $\begin{array}{l}\text { Glifo } \\
\text { mujer }\end{array}$ & $\begin{array}{l}\text { Glosa } \\
\text { mujer }\end{array}$ & Análisis & Logograma & $\begin{array}{c}\text { Glifo } \\
\text { hombre }\end{array}$ & $\begin{array}{l}\text { Glosa } \\
\text { hombre }\end{array}$ & Análisis \\
\hline como & 4 LAGARTO & & & & & & \\
\hline \multirow[t]{3}{*}{ oorn } & 4 FLOR & & & & & & \\
\hline & ¿? CASA & & & & & & \\
\hline & ¿? VENADO & & & & & & \\
\hline 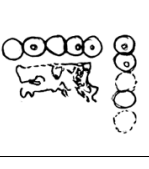 & 10 VIENTO & & & & & & \\
\hline $\begin{array}{r}90000 \\
200 \\
0\end{array}$ & 7 JAGUAR & & & & & & \\
\hline 8 सुक & 3+ LAGARTIJA & & & & & & \\
\hline $\begin{array}{l}958 c \\
6 \\
0\end{array}$ & 6 FLOR & & & & & & \\
\hline & 10 ZOPILOTE & & & & & & \\
\hline$O \underbrace{0}_{n=0}$ & 1 LAGARTO & yacaquihui & $\mathrm{Ya}+\mathrm{ca}+$ quihui & (9) & 1 LAGARTO & yyaciycaqui & Yyaciy+ca+qui \\
\hline 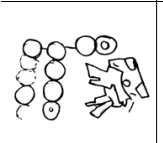 & 12 VIENTO & yyacachi & Yya+ca+chi & $\sigma \leftarrow$ & 1 ÁGUILA & yacasa & $\mathrm{Ya}+\mathrm{ca}+\mathrm{sa}$ \\
\hline
\end{tabular}


Tabla 8. Glifos y glosas calendáricas de los antropónimos del Códice Egerton (continuación)

\begin{tabular}{|c|c|c|c|c|c|c|c|}
\hline Logograma & $\begin{array}{l}\text { Glifo } \\
\text { mujer }\end{array}$ & $\begin{array}{l}\text { Glosa } \\
\text { mujer }\end{array}$ & Análisis & Logograma & $\begin{array}{c}\text { Glifo } \\
\text { hombre }\end{array}$ & $\begin{array}{c}\text { Glosa } \\
\text { hombre }\end{array}$ & Análisis \\
\hline & ¿? PEDERnAL & yagocoxi & $\mathrm{Ya}+\mathrm{go}+\mathrm{coxi}$ & & $7 i ?$ & ....sayu & $i i+i ?+$ sayu \\
\hline 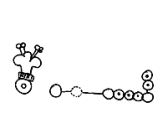 & 12 FLOR & Yya...huaco & Yya+? $;+$ huaco & o0 & 9 LAGARTIJA & yyaciygghy & Yyaciy+g+ghy \\
\hline 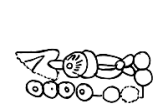 & ¿8? CAÑA & Yasihuiyo & Ya+si+huiyo & 000 ब्ष्षित & ¿? LLUVIA & yу...co & $Y y ?_{i}+? ;+$ co \\
\hline cosoo & 7 ÁGUILA & Ya...sa & $\mathrm{Ya}+\dot{i} ?+\mathbf{s a}$ & 2 & ¿? LAGARTIJA & Yyaciy...ghy & Yyaciy+ ${ }^{?}+$ ghy \\
\hline$\frac{O}{S 0}$ & 3 CAÑA & & & (0) -100 & 3 AGUA & & \\
\hline & 10/11 PERRO & yasihua & Ya+si+hua & 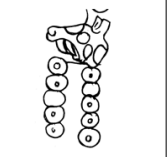 & 13 PERRO & Yyaciygusihua & Yyaciygu+si+hua \\
\hline$\infty, \infty$ & ? CASA & Ya...mao & $\mathrm{Ya}+i ?+\mathbf{m a o}$ & $\begin{array}{l}\left\{\begin{array}{l}\text { 20 } \\
25\end{array}\right. \\
0000\end{array}$ & 4 ZOPILOTE & Yya...ciyqhicuij & Yyacij+qhi+cuij \\
\hline 年( & 2 LLUVIA & yacaco & $\mathrm{Ya}+\mathrm{ca}+\mathbf{c o}$ & 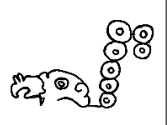 & 7 ZOPILOTE & Yya...cuiy & Yya? $i+? ;+$ cuiy \\
\hline 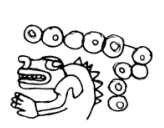 & 10 LAGARTIJA & yyasiqhy & Yya+si+qhy & 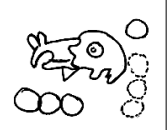 & 9? ZOPILOTE & yyaciyqycuiy & Yyaciy+qy+cuiy \\
\hline oxoog & 8+? AGUA & Yya...tuta & Yya $+i ?+$ tuta & & ¿? CONEJO & yyaciyqhsayu & Yyaciy+qh+sayu \\
\hline & & & & & 3 VENADO & & \\
\hline
\end{tabular}


Tabla 8. Glifos y glosas calendáricas de los antropónimos del Códice Egerton (continuación)

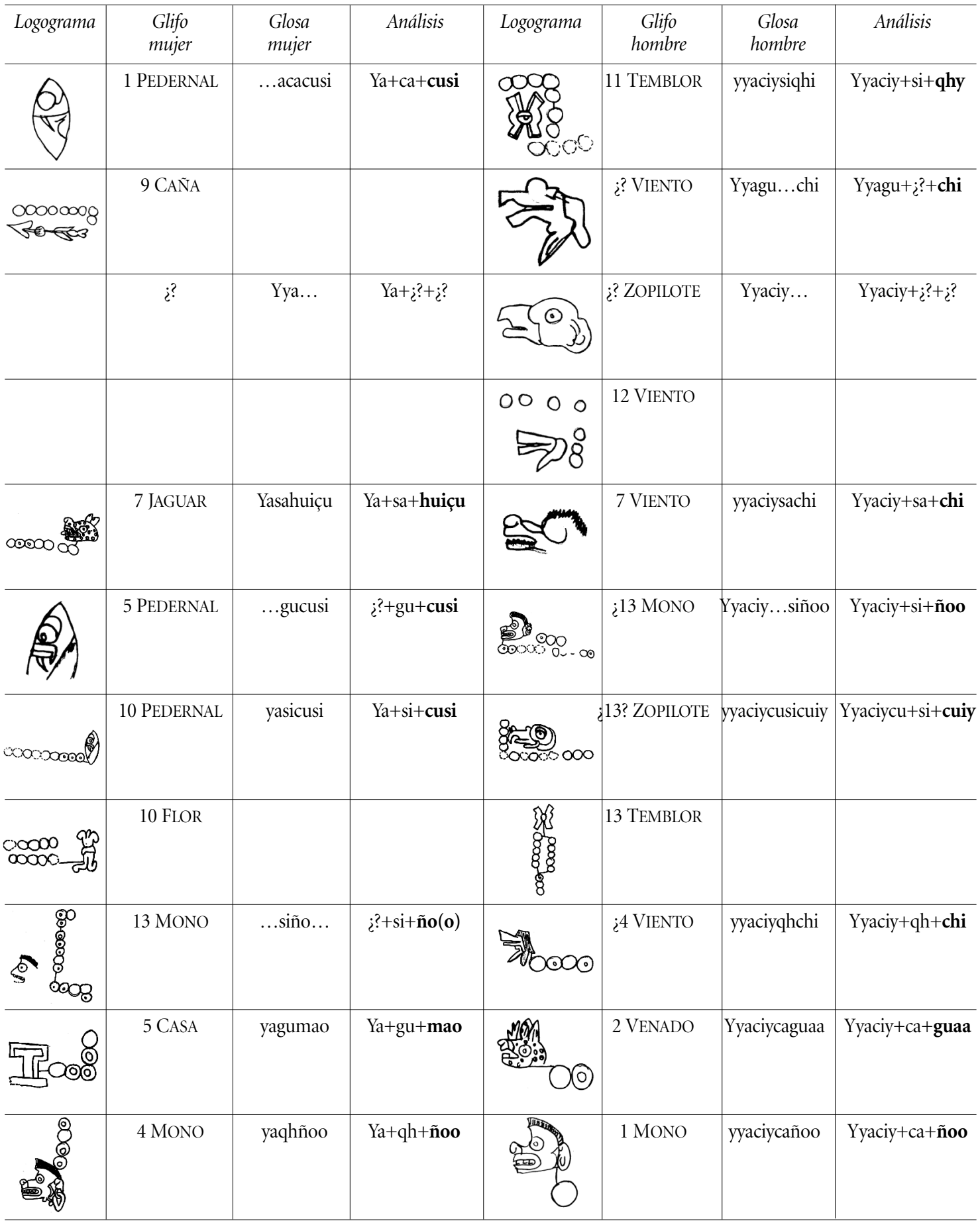


Tabla 8. Glifos y glosas calendáricas de los antropónimos del Códice Egerton (continuación)

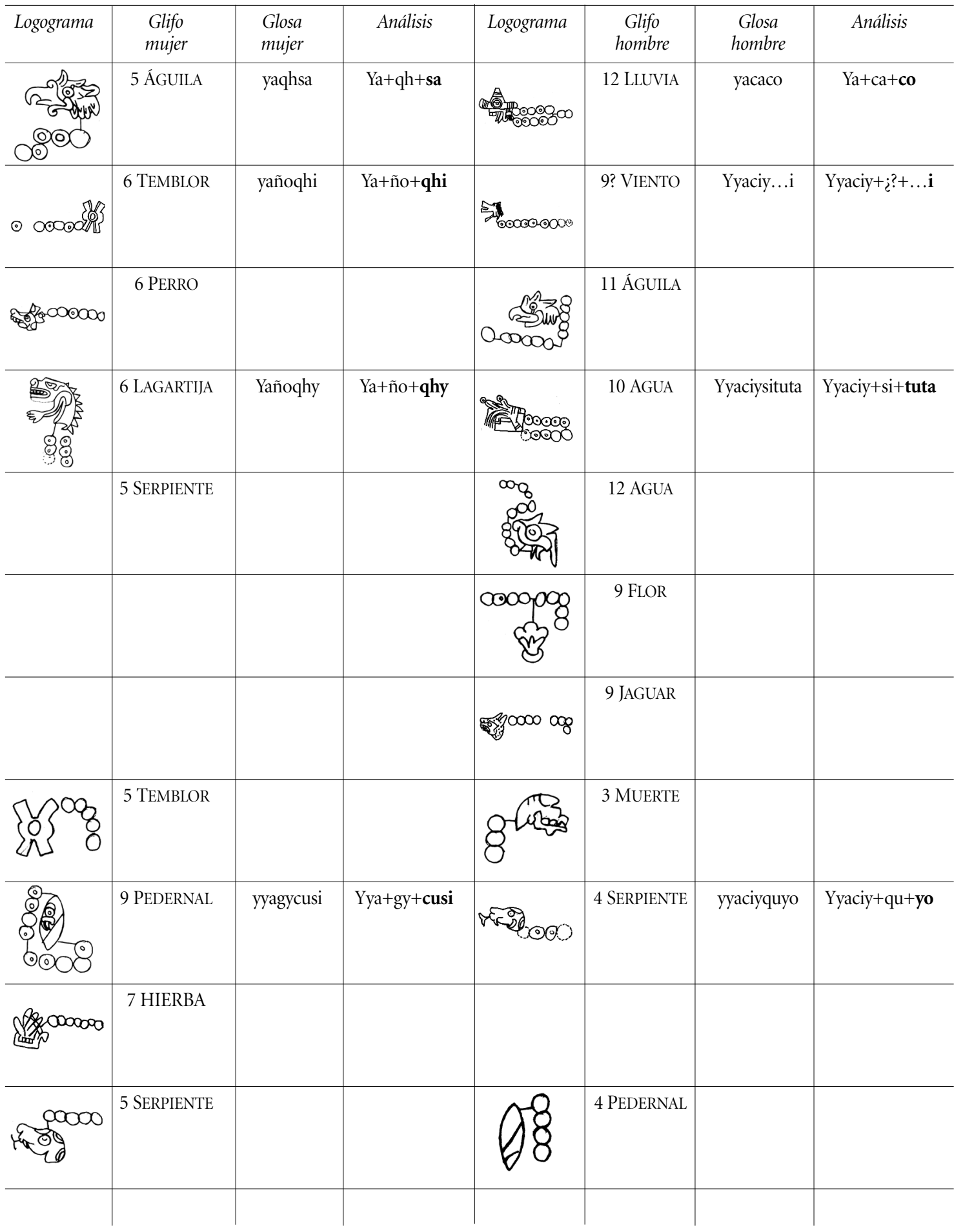


Tabla 8. Glifos y glosas calendáricas de los antropónimos del Códice Egerton (continuación)

\begin{tabular}{|c|c|c|c|c|c|c|c|}
\hline Logograma & $\begin{array}{l}\text { Glifo } \\
\text { mujer }\end{array}$ & $\begin{array}{l}\text { Glosa } \\
\text { mujer }\end{array}$ & Análisis & Logograma & $\begin{array}{l}\text { Glifo } \\
\text { hombre }\end{array}$ & $\begin{array}{l}\text { Glosa } \\
\text { hombre }\end{array}$ & Análisis \\
\hline 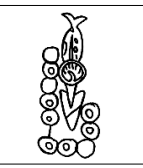 & 11 CAÑA & Ya...sihuiyo & Ya?+si+huiyo & 250 & 6 SERPIENTE & Yyaciyñoyo & Yyaciy+ño+yo \\
\hline \multirow{2}{*}{$\mathrm{x}^{\mathrm{xO} 0}$} & 6 SERPIENTE & ...ñoyo & ¿?+ก̃o+yo & & ¿4? VENADO & y...gua & $Y ?+i ?+$ gua \\
\hline & & & & & 2 LLUVIA & Ya...coco & Ya?+co+co \\
\hline \multirow[t]{3}{*}{ OOO } & 3 VIENTO & ...cochi & $i^{2}+\mathrm{co}+\mathrm{chi}$ & क्षेत8 & ¿9 PERRO & & \\
\hline & ¿4+? AGUA & & & & 4 ÁGUILA & & \\
\hline & ¿? & $\begin{array}{l}\text { yyacoqhy } \\
\text { (Lagartija) }\end{array}$ & Yya-co+qhy & 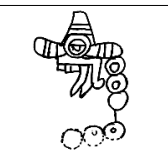 & 6 LLUVIA & yyaciyñogo & Yyaciy+ño+go \\
\hline \multirow[t]{3}{*}{ हुण 8} & 4+? ZOPILOTE & & & 80000 & 8 CASA & & \\
\hline & & & & & 1 LAGARTO & & \\
\hline & 3 ÁGUILA & & & $\begin{array}{r}88 \\
88 \% \\
88 \%\end{array}$ & 13 PEDERNAL & & \\
\hline & 10 TEMBLOR & & & & 5+ VIENTO & & \\
\hline $\begin{array}{l}0000 \\
2380 \\
258\end{array}$ & 6 LAGARTO & & & Soc00 & 5 LAGARTO & & \\
\hline
\end{tabular}


Tabla 9. Información de glifos y glosas calendáricas en el Códice Mixteco Postcortesiano núm. 36

\begin{tabular}{c|c|c|c|c|c}
\hline Logograma & Glifo & Glosa hombre & Análisis & Glosa mujer & Análisis \\
\hline & & Ycoqhi & $\begin{array}{c}\text { Ya+co+qhi } \\
\text { (Temblor) }\end{array}$ & yiaciynacuxi & $\begin{array}{c}\text { Yacíy+na+cuxi } \\
\text { (noble madre } \\
\text { pedernal) }\end{array}$ \\
\hline & yiacaxa & $\begin{array}{c}\text { Yia+ca+xa } \\
\text { (Águila) }\end{array}$ & yiagozayu & $\begin{array}{c}\text { Yia+go+zayu } \\
\text { (conejo) }\end{array}$ \\
\hline \\
\hline
\end{tabular}

Se señalan en negritas los nombres mixtecos encontrados.

Aparecen los nombres para las posiciones 9a (Agua), 15 (Águila) y 19a (Lluvia) con las palabras mixtecas tuta, sa y $c o$, respectivamente, de las cuales no se tenía evidencia en el Lienzo de Nativitas. Otro aspecto que hay que notar es que las dos representaciones glíficas que existen del signo Conejo en las láminas 7 y 15 de este códice prácticamente están borradas, ya que se sobrepusieron a la base de un templo, por lo que no podemos conocer cómo era este logograma en el códice, pero sí conservan su glosa (sayu). Por otro lado, el signo que se usa para el día de la cuarta posición parece más una iguana que una lagartija, por lo que valdría la pena revalorar el nombre de este día de la lista en este códice y considerar el de "Iguana".

\section{La evidencia del Códice Mixteco Postcortesiano} núm. 36 (fig. 7, p. 51)

Este códice del siglo XVI también es histórico-cartográfico. En su centro están representados una iglesia con dos templos mixtecos ${ }^{35}$ y parejas de principales. Asociadas con estas figuras aparecen varias fechas que llevan el glifo del año mixteco y que están vinculadas con glosas. Se trata de los logogramas: Año 8 Pedernal-día 8 Flor y Año 6

${ }^{35}$ Se califican los templos de este códice como mixtecos porque el estilo de representarlos, con su tablero de grecas, es típico de las convenciones de los códices mixtecos prehispánicos. 
Casa-día 7 Hierba (tabla 9, p. 57). Las parejas y los templos tienen glosas en mixteco que los identifican. Abajo, en el centro, se dibuja una serie de 30 tierras o parcelas cruzadas por un río. Quince de éstas — las de la parte su- perior - están incompletas debido a que una sección se perdió y tienen nombres castellanos, mientras que las 15 de abajo, además de que cuentan con glosas en mixteco, están asociadas con cabezas humanas. En los cuatro bor-

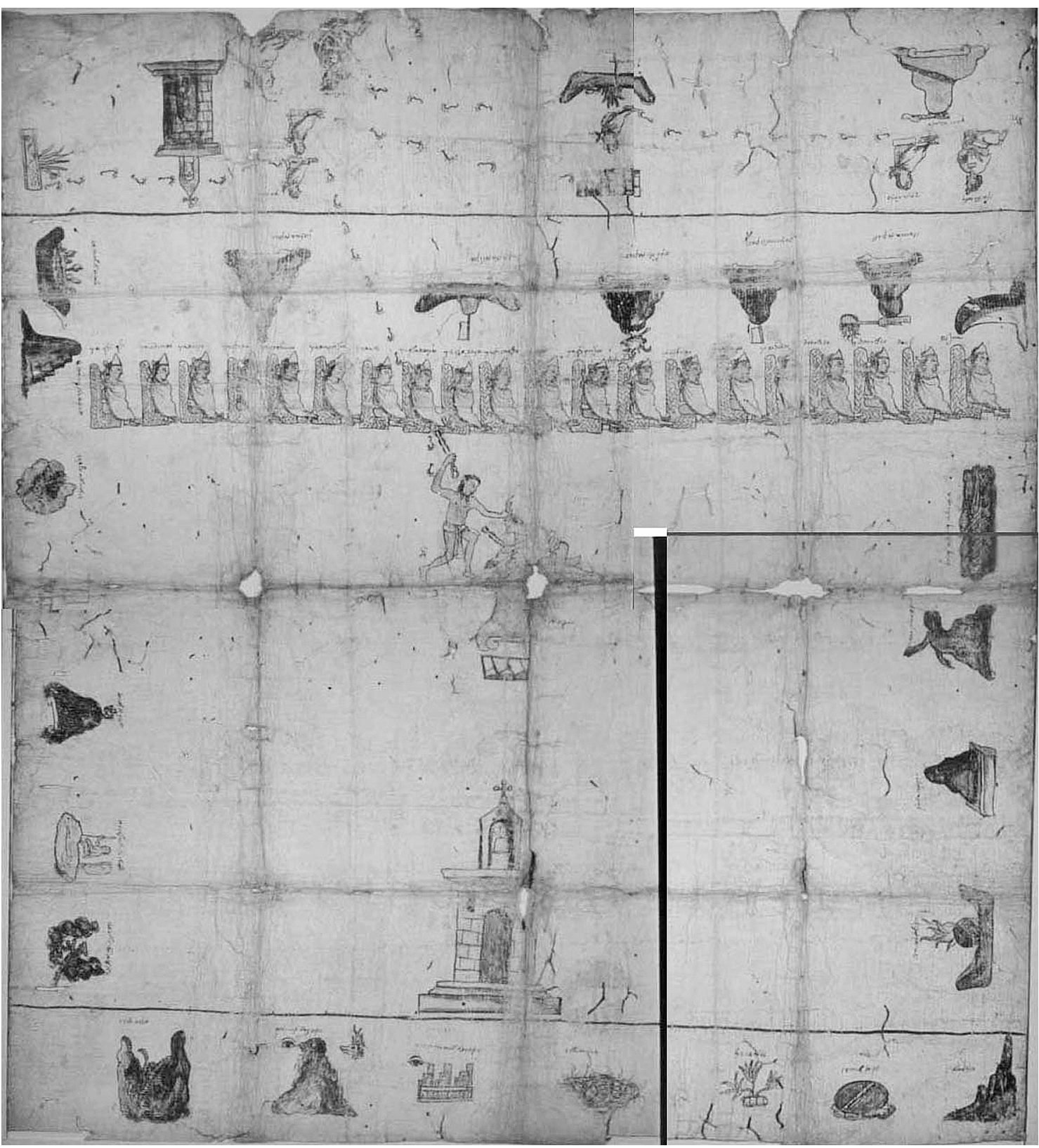

Figura 8. Mapa de Xochitepec. Museo Nacional de Copenhague, Dinamarca. 
Tabla 10. Análisis de las glosas mixtecas calendáricas de los antropónimos del Mapa de Xochitepec

\begin{tabular}{|c|c|c|c|c|}
\hline Sec. & Personaje & Glosa & Análisis & Traducción \\
\hline $\mathrm{M}-\mathrm{H}$ & MUJER & Yañoccoiy & Ya+ño+ccoiy & Sra.+6+Zopilote \\
\hline $\mathrm{M}-\mathrm{H}$ & HOMBRE & Yacañoho & Ya+ño+ñoho & Sr.+1/3/12+Mono \\
\hline $\mathrm{M}-\mathrm{H}$ & HOMBRE & ilegible & & Sr. $+?+?$ \\
\hline $\mathrm{M}-\mathrm{H}$ & HOMBRE & Yaxix... & $\mathrm{Ya}+\mathrm{xi}+\mathbf{x}[\mathbf{a}]$ & Sr.+10/11+Águila \\
\hline $\mathrm{M}-\mathrm{H}$ & HOMBRE & Yacaqu & $\mathrm{Ya}+\mathrm{ca}+\mathbf{q u}$ & Sr. $+1 / 3 / 12+$ Lagartija \\
\hline $\mathrm{M}-\mathrm{H}$ & HOMBRE & Yaca... & $\mathrm{Ya}+\mathrm{ca}+?$ & Sr. $+1 / 3 / 12+?$ \\
\hline H-G & HOMBRE & Yaqhiqhi & Ya+qhi+qhi & Sr.+4+Temblor \\
\hline H-G & HOMBRE & Yañocuxi & Ya+ño+cuxi & Sr.+6+Pedernal \\
\hline $\mathrm{H}-\mathrm{G}$ & HOMBRE & Yaxayo & Ya+xa+yo & Sr. $+7+$ Serpiente \\
\hline $\mathrm{H}-\mathrm{G}$ & HOMBRE & Yaqhoxa & Ya+qho+xa & Sr. $+2 / 3+$ Águila \\
\hline $\mathrm{H}-\mathrm{G}$ & HOMBRE & Yaqhohuaco & Ya+qho+huaco & Sr. $+2 / 3+$ Flor \\
\hline $\mathrm{H}-\mathrm{G}$ & HOMBRE & Yaxaquihco & Ya+xa+quihco & Sr.+7+Lagarto/Temblor? \\
\hline H-G & HOMBRE & Yaxachi & $\mathrm{Ya}+\mathrm{xa}+\mathrm{chi}$ & Sr.+7+Viento \\
\hline $\mathrm{H}-\mathrm{G}$ & HOMBRE & Yaqhoxayu & Ya+qho+xayu & Sr. $+2 / 3+$ Conejo (2 veces) \\
\hline $\mathrm{H}-\mathrm{G}$ & HOMBRE & Yaqhiquaho & Ya+qhi+quaho & Sr.9/4+Casa \\
\hline $\mathrm{H}-\mathrm{G}$ & HOMBRE & Ya...yo & $\mathrm{Ya}+?+$ yo & Sr+?+Serpiente \\
\hline $\mathrm{H}-\mathrm{G}$ & HOMBRE & Yaqhiqhihui & Ya+qhi+qhihui & Sr.+9/4+Lagarto \\
\hline H-G & HOMBRE & Yaqhaqhuy & Ya+qha+qhuy & Sr. $+1 / 3 / 12+$ Zopilote \\
\hline H-G & HOMBRE & Yañohuiyo & Ya+ño+huiyo & Sr.+6+Caña \\
\hline $\mathrm{H}-\mathrm{G}$ & HOMBRE & Yaxihuiço & Ya+xi+huiço & Sr.+10/11+Jaguar \\
\hline $\mathrm{H}-\mathrm{G}$ & HOMBRE & Yaxahuaco & Ya+xa+huaco & Sr. $+7+$ Flor \\
\hline
\end{tabular}

Se señalan en negritas los nombres mixtecos encontrados.

des del lienzo aparecen varios topónimos representados por sus glifos y glosas en mixteco.

En el análisis realizado a este códice detectamos nueve registros calendáricos, de los cuales uno se trata de glifos (numeral y día) asociados con una glosa mixteca. Otros cuatro son glifos de fechas sin glosas en mixteco, y los cuatro restantes son solamente glosas calendáricas de los antropónimos de los personajes representados (tabla 9, p. 57). Podemos observar que estos textos ya no están asociados con logogramas mixtecos, excepto uno, en el que al personaje al que se relacionan se le identifica además con un sobrenombre. Las evidencias encontradas en este códice permiten identificar la estructura de los nombres calendáricos en mixteco, pero no resultan tan útiles como clave para conocer el nombre de los logogramas de días mixtecos, excepto en un caso. Podemos señalar que este códice confirma el nombre de una de las variantes de la glosa del día Muerte encontrada en el Lienzo de $\mathrm{Na}$ tivitas, que es el término mixteco maho. 


\section{OTROS CÓDICES CON GLOSAS CALENDÁRICAS DE LA MIXTECA BAJA}

En este grupo podemos considerar al Mapa de Xochitepec, ya estudiado por Alfonso Caso en la década de 1950, y el Mapa de San Vicente el Palmar, inédito hasta ahora, ya que ambos documentos son evidencia invaluable de los registros en caracteres alfabéticos coloniales en lengua mixteca de los nombres calendáricos de los días del calendario ritual, pero ya no aportan claves que permitan establecer una correspondencia con los signos calendáricos empleados en la escritura logográfica mixteca, pues ésta no se representó y fue sustituida por las glosas. No obstante, ambos códices ayudan a confirmar el uso de los nombres encontrados en los códices anteriores, así como sus variantes lingüísticas.

Mapa de Xochitepec (fig. 8, p. 58)

Este códice del siglo XVI también tiene una temática cartográfica-histórica. Está compuesto por tres partes: una sección mítica-histórica en la parte superior; una histórica al centro del documento, donde está la iglesia de Xochitepec y algunos personajes - en el lugar central aparece una escena de sometimiento y, encima de ésta, una serie de señores sentados en asientos de petate con respaldo, que llevan sus nombres con glosas en mixteco; los últimos señores del lado derecho tienen glosas ya en español, con los nombres castellanos de sus bautizos ${ }^{36}$ - y la sección cartográfica, con los diferentes topónimos que rodean la escena central.

\footnotetext{
${ }^{36} \mathrm{El}$ análisis de este lienzo se pudo realizar con las fotografías a color del archivo del Museo Nacional de Dinamarca proporcionadas por Michel Oudijk en junio de 2001, las cuales permitieron realizar una observación más detallada del lienzo. También ha sido de mucha utilidad el registro gráfico realizado de una copia de dicho mapa en blanco y negro, elaborada quizás por Alfonso Caso, y que se encuentra en la mapoteca de la Subdirección de Documentación de la Biblioteca Nacional de Antropología e Historia. Dicha copia no estaba clasificada, ya que no se sabía qué era lo que contenía. Fue Manuel Hermann quien me comentó en 1998 que existía esta copia en el Museo. Agradezco a las autoridades de la Biblioteca Nacional de Antropología e Historia la disponibilidad otorgada para consultar dicha copia.
}

Aunque existen diferencias entre las paleografías propuestas y la de los estudios anteriores ${ }^{37}$ respecto a los antropónimos de los señores, en este trabajo no se comentarán por falta de espacio. Me importa más señalar que de las 22 glosas calendáricas que tienen estos gobernantes, sólo una es completamente ilegible, pero en el resto podemos reconocer 14 nombres de días diferentes de los 20 que tiene la lista. Se trata de las siguientes posiciones: $1^{\mathrm{a}}$ (Lagarto), 2a (Viento), 3a (Casa), 4a (Lagartija), $5^{\mathrm{a}}$ (Ser-

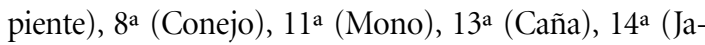
guar), 15a (Águila), 16a (Zopilote), 17a (Temblor), $18^{\mathrm{a}}$ (Pedernal), 20a (Flor) (tabla 10, p. 79). Los nombres que más se repiten en este códice para nombrar a los señores son los días Serpiente, Conejo, Águila, Zopilote y Flor. Se confirma el nombre de Águila con el término mixteco $x a$; se usa la variante quaho para el día Casa, como en los códices Sierra y Nativitas; se presenta el uso de Mono como ñoho, y la variante quihui para el día Lagarto, ya detectada en el códice Egerton.

\section{Mapa de San Vicente el Palmar (fig. 9)}

Éste es otro documento del corpus que hemos tratado y que todavía se conservaba en la población del mismo nombre $^{38}$. También del siglo XVI, tiene un contenido de carácter histórico-cartográfico. Este códice ya había sido reportado por Smith ${ }^{39}$ y existe una copia de este mapa en el Archivo Agrario Nacional de Oaxaca (Arano), que se ha denominado Lienzo 57 glosas, y que, en comparación con el original, le faltan varios detalles en los glifos y en las glosas. Este mapa colonial presenta en la parte central dos listas largas de señores, representadas por una serie de cabezas con tocado y glosas calendáricas en lengua mix-

\footnotetext{
37 Gómez de Orozco, 1952, 1955; Caso, 1958

38 Agradecemos a las autoridades y a la población de San Vicente el Palmar su hospitalidad e interés por el estudio de este mapa colonial y por su disponibilidad durante el registro gráfico y fotográfico del mapa original hacia fines de 2004 y mediados de 2005. En este registro participaron Itzel González, Rosalba Sánchez, Julieta León y la restauradora Marie Vander Meeren como colaboradoras del proyecto "Geografía histórica de la Mixteca Baja: toponimia y espacio políticos del siglo VIII al XVI", de la ENAH, del cual soy responsable.

${ }^{39}$ Cf. Smith y Parmenter, 1991.
} 


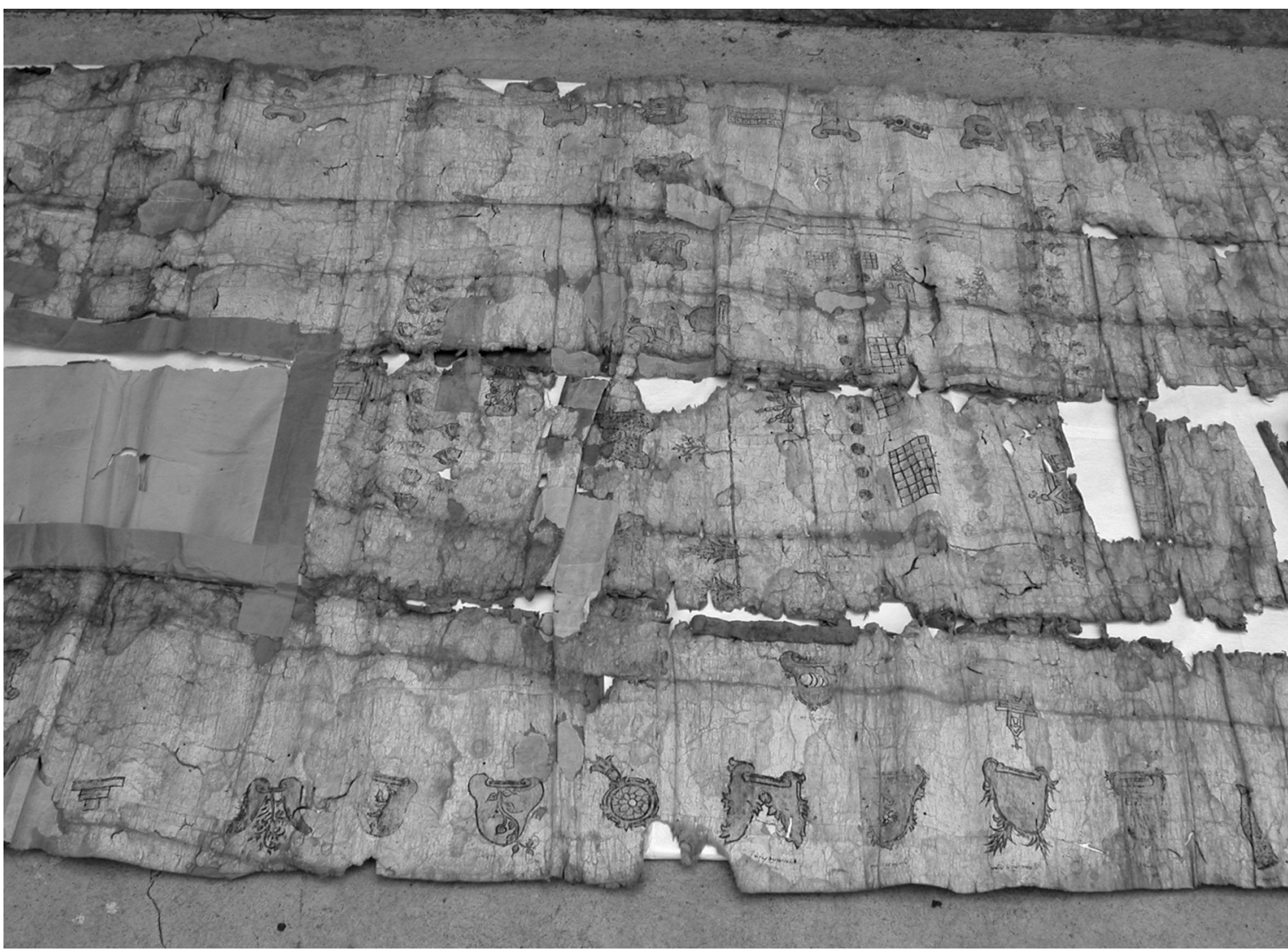

Figura 9. Mapa de San Vicente el Palmar, Municipio de Teozatlán, Oaxaca, mayo de 2005. Proyecto "Geografía histórica de la Mixteca Baja: toponimia y espacio político del siglo VIII al XVI", ENAH.

teca, que se asocian a dos grandes construcciones religiosas: una ubicada en la zona central superior y otra en la zona central inferior. El deterioro del documento y el paso del tiempo han borrado muchas de estas glosas, volviendo algunas prácticamente ilegibles a pesar de que, para su lectura, se utilizó luz ultravioleta, que permite ver los trazos de las letras en tintas ferrogálicas desgastadas ${ }^{40}$. El sentido de la lectura que se ha propuesto en cada una de las listas genealógicas del documento ha sido en bustrofedon, de abajo hacia arriba, hasta llegar a los señores que ya tienen nombres españoles. La genealogía del centroinferior está distribuida en tres renglones, con 21 cabezas

${ }^{40}$ Comentario personal de Marie Vander Meeren, 2005. en total asociadas con sus glosas (tabla 11, pp. 62-63), y la genealogía del centro-superior con una distribución también en tres renglones, tiene un total de 23 cabezas con sus respectivas glosas (tabla 12, pp. 64-65). Se debe señalar que es posible que haya tres cabezas más en la genealogía del centro-superior, pero se encuentran tapadas por una cinta adhesiva de cartón, colocada en eventos posteriores en varias partes del mapa ${ }^{41}$.

En total, tomando en cuenta ambas listas, existen 46 antropónimos, de los cuales cuatro ya son nombres en espa-

\footnotetext{
${ }^{41}$ En noviembre de 2005, cuando el mapa estaba en restauración en la Biblioteca Burgoa, pudo desprenderse uno de los pegotes, y quedaron al descubierto dos cabezas más, con lo que suman 25 cabezas en total. Estas nuevas cabezas no tenían glosas asociadas.
} 
Tabla 11. Análisis de las glosas mixtecas de la genealogía inferior del Mapa de San Vicente el Palmar

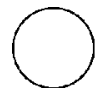<smiles>C1CCCCCCCC1</smiles>

GI 21

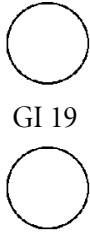

GI 3

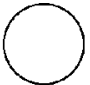

GI 18

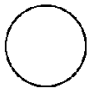

GI 4

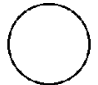

GI 17

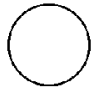

GI 5<smiles>C1CCCCCC1</smiles>

GI 16<smiles>C1CCCCC1</smiles>

GI 6

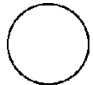

GI 15

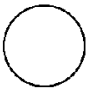

GI 7<smiles>C1CCCCC1</smiles>

GI 14<smiles>C1CCCCC1</smiles>

GI 8<smiles>C1CCCCC1</smiles>

GI 13

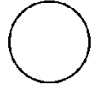

GI 9<smiles>C1CCCCC1</smiles>

GI 12

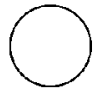

GI 10

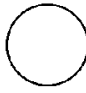

GI 11

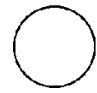

GI 2<smiles>C1CCCCCCCC1</smiles>

GI 1

\begin{tabular}{|c|c|c|c|}
\hline Clave & Glosa & Análisis & Traducción \\
\hline GI 1 & roto & & \\
\hline GI 2 & Nombre español & & \\
\hline GI 3 & $\ldots$ yo & $\begin{array}{l}{[\mathrm{Ya}]+\dot{i} ?+\text { yo }} \\
\text { Señor } i \text { ? Serpiente }\end{array}$ & Señor $+\dot{\imath} ?+$ Serpiente \\
\hline GI 4 & $\begin{array}{l}\text { Ya dzi[n]...a } \\
\text { Ya+dzi+m...a }\end{array}$ & $\begin{array}{l}\text { Ya dzi }[\mathrm{m}] \ldots \mathbf{a} \\
\text { Señor+10/11+Casa/Muerte }\end{array}$ & $\begin{array}{l}\text { Señor }+10 / 11+\text { Casa } \\
\text { Señor } 10 / 11 \text { Muerte }\end{array}$ \\
\hline GI 5 & Ya qhi ñoo & $\begin{array}{l}\text { Ya+qhi+ñoo } \\
\text { Señor+4+Mono }\end{array}$ & Señor 4 Mono \\
\hline GI 6 & $\begin{array}{l}\text { Y[a] uxi vaco } \\
\S\end{array}$ & $\begin{array}{l}\text { Ya+uxi+vaco } \\
\text { Señor+10/11+Flor }\end{array}$ & Señor 10/11 Flor \\
\hline GI 7 & Yaca viço & $\begin{array}{l}\text { Ya+ca+vico } \\
\text { Señor+1/2/3/12+Jaguar }\end{array}$ & Señor $1 / 2 / 3 / 12$ Jaguar \\
\hline$\overline{\text { GI } 8}$ & Ya na pa & $\begin{array}{l}\text { Ya+na+pa } \\
\text { Señor+8+Águila/Lluvia? }\end{array}$ & Señor 8 Águila/Lluvia? \\
\hline GI 9 & Ya qho yo & $\begin{array}{l}\text { Ya+qho+yo } \\
\text { Señor+2/3+Serpiente }\end{array}$ & Señor $2 / 3$ Serpiente \\
\hline$\overline{\text { GI } 10}$ & (Ya) co noho & $\begin{array}{l}\text { Ya+co+noho } \\
\text { Señor+2/3+Mono }\end{array}$ & Señor $2 / 3$ Mono \\
\hline$\overline{\text { GI } 11}$ & Ya no quaa & $\begin{array}{l}\text { Ya+no+quaa } \\
\text { Señor+6+Venado }\end{array}$ & Señor 6 Venado \\
\hline GI 12 & $\begin{array}{l}\text { Ya [o]ho...o } \\
\text { Ya [o]ho...u/v }\end{array}$ & $\begin{array}{l}\text { Ya+oho+uv } \\
\text { Señor+5+Perro? }\end{array}$ & Señor 5 ¿Perro? \\
\hline$\overline{\text { GI } 13}$ & Ya ca quihui & $\begin{array}{l}\text { Ya+ca+quihui } \\
\text { Señor+1/2/3/12+Lagarto }\end{array}$ & Señor 3/12 Lagarto \\
\hline GI 14 & Ya qhi quau & $\begin{array}{l}\text { Ya+qhi+quau } \\
\text { Señor+4+Casa }\end{array}$ & Señor 4 Casa \\
\hline GI 15 & Ya qho xico & $\begin{array}{l}\text { Ya+qho+xico } \\
\text { Señor }+2 / 3+¿ \text { una inversión de coxi? }\end{array}$ & Señor $2 / 3$ Pedernal \\
\hline GI 16 & $\ldots[\mathrm{qu}] \mathrm{a}$ & $\begin{array}{l}{[\mathrm{Ya}]+\dot{i} ?+\text { qua }} \\
\text { Señor+ }+ \text { ? + Venado }\end{array}$ & Señor $i$ ? Venado \\
\hline
\end{tabular}


Tabla 11. Análisis de las glosas mixtecas de la genealogía inferior del Mapa de San Vicente el Palmar (continuación)

\begin{tabular}{|c|c|c|c|}
\hline Clave & Glosa & Análisis & Traducción \\
\hline GI 17 & Ya xa qhi & $\begin{array}{l}\text { Ya+xa+qhi } \\
\text { Señor+7+Temblor }\end{array}$ & Señor 7 Temblor \\
\hline GI 18 & [Ya] Xi huiço /çu & $\begin{array}{l}\text { Ya+xi+huiçu/huiço } \\
\text { Señor+10/11+Jaguar }\end{array}$ & Señor 10/11 Jaguar \\
\hline GI 19 & ...ho... & $\begin{array}{l}{[Y a]+\ldots h o+i ?} \\
\text { Señor }+2 / 3+i ?\end{array}$ & Señor $2 / 3 i ?$ \\
\hline GI 20 & ...ina & $\begin{array}{ll}{[Y a]+i ?+\text { ina } /} & {[Y a]+i \ldots i ?+\text { na }} \\
\text { Señor }+i ?+\text { Perro } & \text { Señor }+4 / 9 / 10 / 11+\text { na }\end{array}$ & $\begin{array}{l}\text { Señor } i \text { ? Perro } \\
\text { Señor } 4 / 9 / 10 / 11 \text { Perro }\end{array}$ \\
\hline GI 21 & [ilegible] & & \\
\hline
\end{tabular}

Se señalan en negritas los nombres mixtecos encontrados.

ñol, dos no tienen glosas asociadas y el resto de las glosas (40) están en lengua mixteca. De este último grupo, dos están completamente ilegibles y en once la lectura paleográfica es incompleta, ya que a veces sólo se conserva una parte de las tres palabras que conforman estos nombres calendáricos. Quedan, entonces, 27 registros calendáricos completos, entre los cuales hay 14 términos diferentes para nombrar los días, que corresponden a las siguientes posiciones de la lista: $1^{\mathrm{a}}$ (Lagarto), $2^{\mathrm{a}}$ (Viento), $3^{\mathrm{a}}$ (Casa), $4^{a}$ (Lagartija), 5a (Serpiente), 7a (Venado), 10a (Perro), 11'a (Mono), 14a (Jaguar), 15a (Águila), 16a (Zopilote), 17a (Temblor), 18 (Pedernal) y 20a (Flor). Tentativamente, podrían estar dos días más de la lista, el de la $6^{a}$ posición (Muerte) y el de la 19a (Lluvia).

Asimismo, podemos notar que en la lista de nombres de la parte centro-inferior hay tres términos: $p a$, xico e ina, que no habían aparecido en los otros documentos analizados como nombres de días. Una posibilidad es que, en el caso del primer término, se trate del día $c a^{42}$, pero que el glosista haya puesto una $p$ en lugar de $q^{43}$. El segundo es posible que se trate de una inversión hecha por el escribano de la palabra mixteca coxi, Pedernal. Y en el

\footnotetext{
${ }^{42}$ Este nombre de día ca puede ser para Águila, que en otros documentos se reporta como $x a$, o bien para Lluvia, que en el Códice Egerton aparece solamente como co.

${ }^{43}$ En algunos documentos de la Mixteca aparecen palabras con una $p$ que debería ser q. Comunicación personal de Rosalba Sánchez Flores, 2007.
}

tercer caso, la palabra ina aparentemente no es parte de un lenguaje especial y significa perro. $\mathrm{Al}$ respecto, también se debe señalar que en este análisis de las glosas calendáricas se detectaron números que no pertenecen al lenguaje especial, por lo menos en una ocasión ${ }^{44}$. Otra posibilidad es que la $i$ sea parte de los numerales $4,9,10 \mathrm{u}$ 11 , y el nombre del día sea solamente $n a$, como la variante del nombre de Perro detectada en el Códice Muro ${ }^{45}$. Este análisis muestra que el glosista, aparentemente por falta de espacio, registró la glosa Yaxa, que es un nombre calendárico incompleto ya que le falta el nombre del día y sólo existe la partícula reverencial ( $y a-$ señor) y el numeral $(x a-7)$, o bien le falta el numeral y sólo tenemos la partícula reverencial y el nombre de día ( $x a$ - Águila).

También podemos notar que en los nombres para los días Muerte y, en otro término, para el día Perro, la glosa está incompleta, pero las letras que aún se distinguen permiten suponer que se trata de las palabras para estos dos días. En el caso de contar con las letras finales de las glosas hemos propuesto varios días posibles, entre ellos la posición $8^{\mathrm{a}}$ (Conejo) y la $13^{\mathrm{a}}$ (Caña), pero que no son nombres constantes en este mapa. Los nombres más repetidos en los registros antroponímicos de este documento son los días Serpiente, Lagartija, Temblor, Jaguar y Águila.

\footnotetext{
${ }^{44}$ Pero que no discutiremos por el momento en este trabajo.
}

${ }^{45}$ Cf. Hermann, 2003. 
Tabla 12. Análisis de las glosas mixtecas de la genealogía superior del Mapa de San Vicente el Palmar

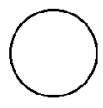

GS 25

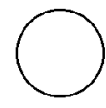

GS 24

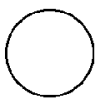

GS 23

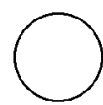

GS 22

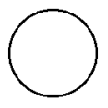

GS 21<smiles>C1CCCCCCC1</smiles>

GS 20

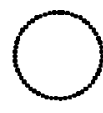

GS 19<smiles>C1CCCCCCC1</smiles>

GS 18<smiles>C1CCCCCCC1</smiles>

GS 17<smiles>C1CCCCCCC1</smiles>

GS 16<smiles>C1CCCCCCC1</smiles>

GS 6

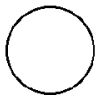

GS 7

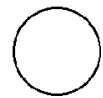

GS 8

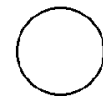

GS 9

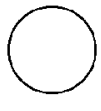

GS 10

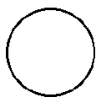

GS 11

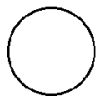

GS 12

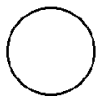

GS 13

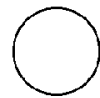

GS 14

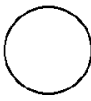

GS 15<smiles>C1CCCCCCC1</smiles>

GS 5<smiles>C1CCCCCCC1</smiles>

GS 4

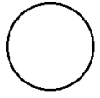

GS 3

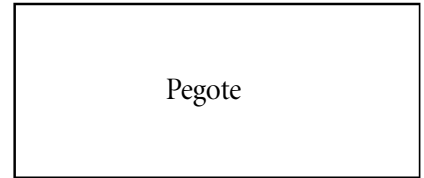

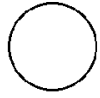

GS 2<smiles>C1CCCCCCC1</smiles>

GS 1

\begin{tabular}{|c|c|c|c|}
\hline Clave & Glosa & Análisis & Traducción \\
\hline GS 1 & Sin glosa & & \\
\hline GS 2 & Sin glosa & & \\
\hline \multicolumn{4}{|l|}{ Pegote } \\
\hline GS 3 & Nombre en español & & \\
\hline GS 4 & Nombre en español & & \\
\hline GS 5 & Nombre en español & & \\
\hline GS 6 & [Ya]xayo & $\begin{array}{l}\text { Ya+xa+yo } \\
\text { Señor+7+Serpiente }\end{array}$ & Señor 7 Serpiente \\
\hline GS 7 & Ya...h & $\begin{array}{l}\text { Ya+? } i+\ldots h ? \\
\text { Señor }+i ?+i \text { Lagarto/Casa/Lagartija/Muerte/Temblor? }\end{array}$ & $\begin{array}{l}\text { Señor } i ?: \text { Lagarto/Casa/ } \\
\text { Lagartija/Muerte/Temblor? }\end{array}$ \\
\hline GS 8 & Ya qha qho & $\begin{array}{l}\text { Ya+qha+qho } \\
\text { Señor }+1 / 3 / 12+i \text { Lagartija/Temblor? }\end{array}$ & Señor $1 / 3 / 12$ ¿Lagartija/Temblor? \\
\hline GS 9 & Ya...qhi & $\begin{array}{l}\text { Ya+? }{ }^{+}+\mathbf{q h i} \\
\text { Señor+ } i ?+\text { Lagartija/Temblor }\end{array}$ & Señor ¿? ¿Lagartija/Temblor \\
\hline GS 10 & Ya...çu & $\begin{array}{l}\text { Ya+? } \dot{i}+\ldots \text { çu } \\
\text { Señor }+i ?+i \text { Jaguar? }\end{array}$ & Señor ¿? ¿Jaguar? \\
\hline GS 11 & Ya...a & $\begin{array}{l}\text { Ya }+? i+\ldots \text { a } \\
\text { Señor }+i ?+i \text { Águila/Lluvia? }\end{array}$ & Señor $i ?:$ Águila/Lluvia? \\
\hline GS 12 & [ilegible] & & \\
\hline GS 13 & Ya qho xi & $\begin{array}{l}\text { Ya+qho+xi } \\
\text { Señor }+2 / 3+\text { Viento }\end{array}$ & Señor $2 / 3$ Viento \\
\hline GS 14 & [Ya]xa qh & $\begin{array}{l}\text { Ya+xa+qh } \\
\text { Señor+7+Lagartija }\end{array}$ & Señor 7 Lagartija \\
\hline GS 15 & $\begin{array}{l}\text { Ya...x...o/ } \\
\text { Yax...o }\end{array}$ & $\begin{array}{l}\text { Ya }+x \ldots+\ldots o \\
\text { Señor }+7 / 10 / 11+i \text { Casa/Serpiente/Mono/Caña/Jaguar/Flor? }\end{array}$ & $\begin{array}{l}\text { Señor } 7 / 11 / 12 \text { ¿Casa/Serpiente/Mono } \\
\text { /Caña/Jaguar/Flor? }\end{array}$ \\
\hline
\end{tabular}


Tabla 12. Análisis de las glosas mixtecas de la genealogía superior del Mapa de San Vicente el Palmar (continuación)

\begin{tabular}{|c|c|c|c|}
\hline Clave & Glosa & Análisis & Traducción \\
\hline GS 16 & Ya... & $\begin{array}{l}\text { Ya... } \\
\text { Señor }\end{array}$ & Señor $i ? i ?$ \\
\hline GS 17 & Ya coxa & $\begin{array}{l}\text { Ya+co+xa } \\
\text { Señor }+1 / 2 / 3+\text { Águila }\end{array}$ & Señor $1 / 2 / 3$ Águila \\
\hline GS 18 & ...quii & $\begin{array}{l}{[Y a]+i ?+\text { quii }} \\
\text { Señor }+i ?+\text { Zopilote }\end{array}$ & Señor ¿? Zopilote \\
\hline GS 19 & $\ldots \mathrm{u}$ & $\begin{array}{l}{[Y a]+? ;+\ldots \mathbf{u}} \\
\text { Señor }+i ?+i \text { Lagartija/Conejo? }\end{array}$ & Señor $i ? ~ ¿ L a g a r t i j a / C o n e j o ?$ \\
\hline GS 20 & Ya... & $\begin{array}{l}\text { Ya }+i ?+i ? \\
\text { Señor }+i ?+i ?\end{array}$ & Señor $i ? i ?$ \\
\hline GS 21 & Ya [q]ho...a & $\begin{array}{l}\text { Ya+qho+...a } \\
\text { Señor }+2 / 3+i \text { Águila/Lluvia? }\end{array}$ & Señor $2 / 3$ iÁguila/Lluvia? \\
\hline GS 22 & Ya xa & $\begin{array}{l}\text { Ya+xa } \\
\text { Señor+7/Señor+Águila }\end{array}$ & Señor 7 / Señor Águila \\
\hline GS 23 & Ya xa yo & $\begin{array}{l}\text { Ya+xa+yo } \\
\text { Señor }+7+\text { Serpiente }\end{array}$ & Señor 7 Serpiente \\
\hline GS 24 & Ya xa .... & $\begin{array}{l}\mathrm{Ya}+\mathrm{xa}+i ? \\
\mathrm{Ya}+7+? i\end{array}$ & Señor $7 i ?$ \\
\hline GS 25 & Yya xi que & $\begin{array}{l}\text { Yya+xi+que } \\
\text { Señor+10/11+Lagartija }\end{array}$ & Señor 10/11 Lagartija \\
\hline
\end{tabular}

Se señalan en negritas los nombres mixtecos encontrados.

\section{COMENTARIOS FINALES}

Después de este análisis sistemático de los 20 días de la lista del ciclo de 260 días registrados en los códices de la Mixteca (Vindobonensis, Nuttall, Bodley, Selden, Colombino, Becker I, Lienzo de Santa María Nativitas y Sierra) y, en particular, los de la Mixteca Baja (Becker II, Tulane, Egerton, Mixteco Poscortesiano núm. 36, Mapa de Xochitepec y Mapa de San Vicente el Palmar), se pueden precisar los siguientes aspectos (tabla 13, pp. 86-89):

a) A pesar de las diferencias caligráficas de los logogramas de los 20 días representados en los códices prehispánicos y coloniales, debidas a las distintas manos con las que fueron pintados, todos los logogramas muestran una fuerte continuidad, casi inalterable, en todas sus características intrínsecas y en los principios escriturarios que los norman (por citar algunos, rotación, inver- sión, pars pro toto). El análisis mostró que para el día Casa de la tercera posición existen dos tipos de construcciones para representarlo: de techo plano o curvo. Se señala una sola alteración en el día Muerte, de la sexta posición: representado de perfil en la mayoría de los códices, en la Colonia aparece, en un solo documento, el logograma de cráneo visto de frente. Por otro lado, el análisis iconográfico del cuarto día, reconocido tradicionalmente como una lagartija, al parecer, se asemeja más en los documentos de la Mixteca Baja a una iguana por las grandes patas con garras y la piel escamosa y puntiaguda de su torso.

b) Con respecto al registro en caracteres latinos en mixteco que proporcionan muchos de estos códices coloniales, en las fechas y antropónimos podemos notar una variación muy amplia en el uso de las grafías para registrar los sonidos del mixteco, tanto al interior de cada documento como entre los distintos códices y fuen- 
Tabla 13. Análisis comparativo de los glifos

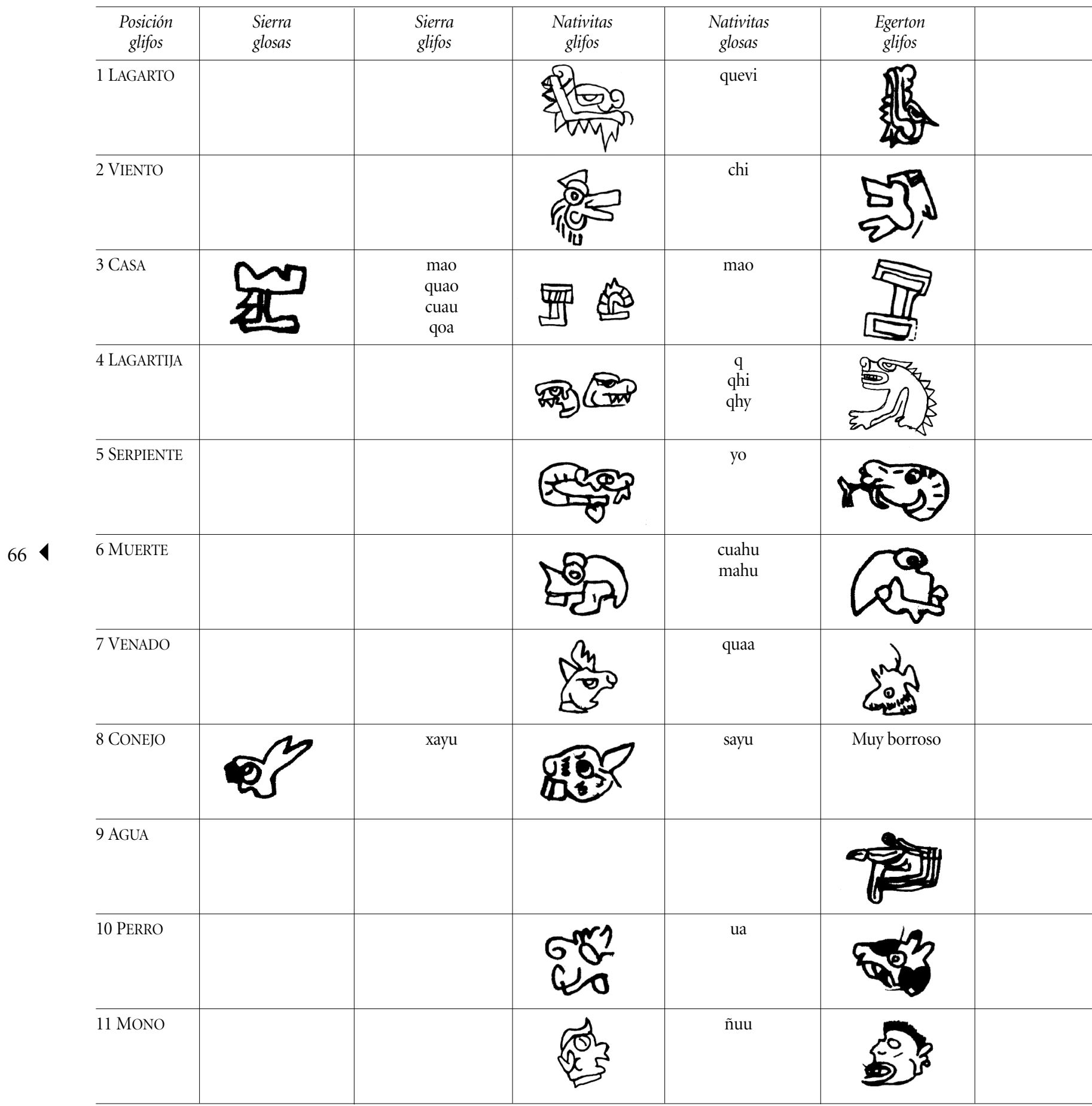


y glosas de los códices estudiados

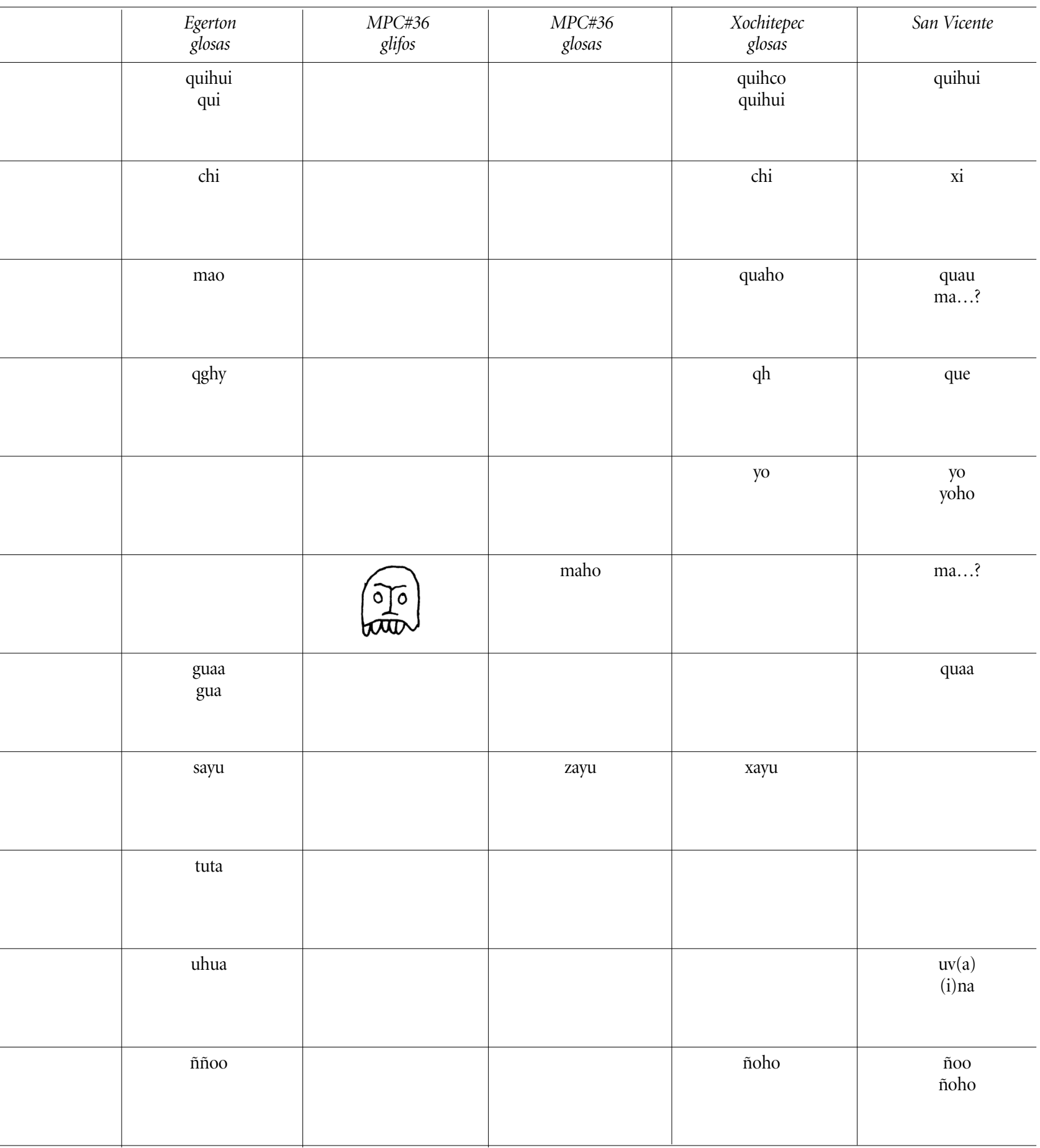


Tabla 13. Análisis comparativo de los glifos

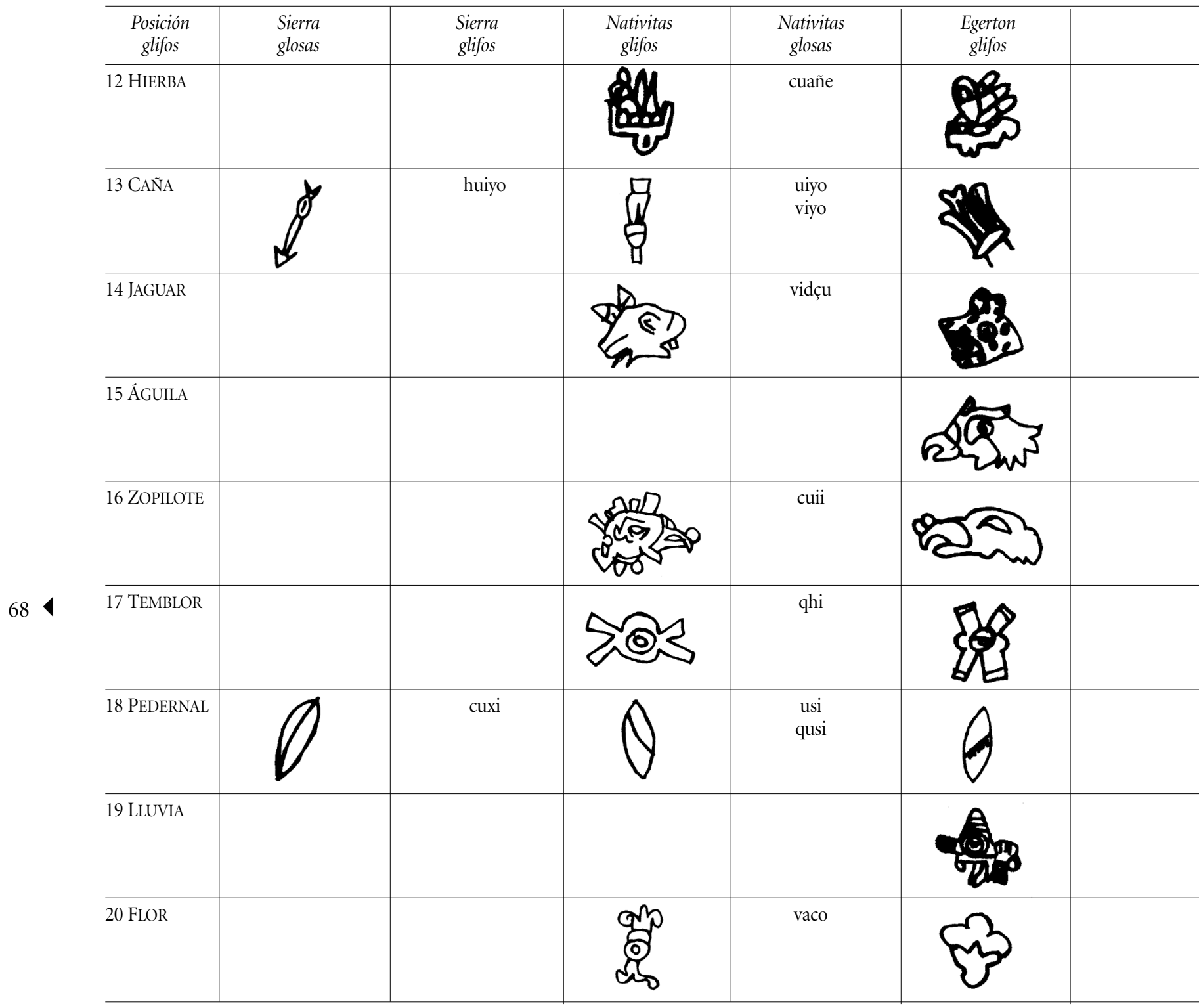


y glosas de los códices estudiados (continuación)

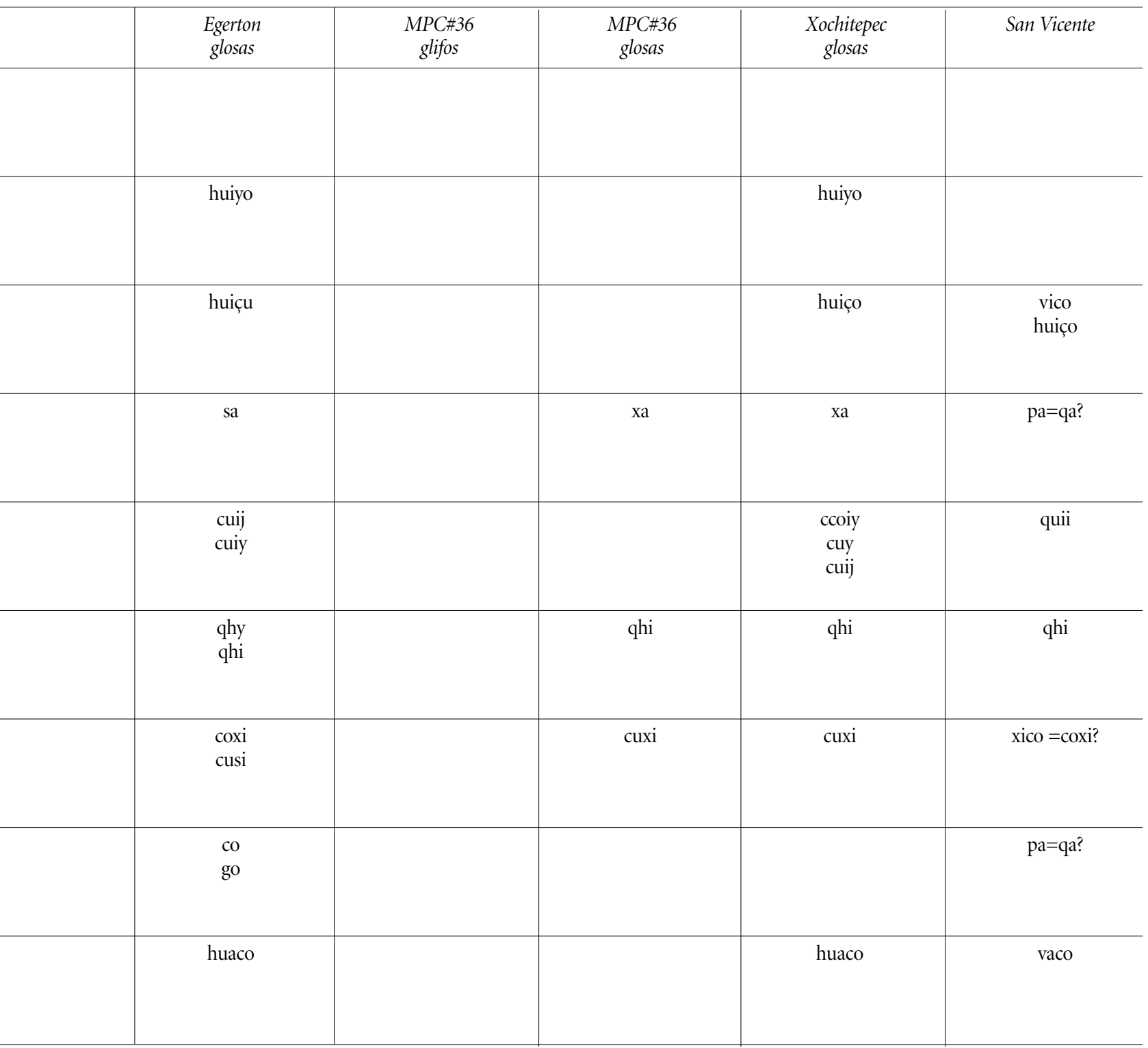


tes coloniales, como las Relaciones Geográficas, que no incorporé en este análisis de los días. Ya Arana y Swadesh habían señalado estas inconsistencias mostrando que las grafías pueden utilizarse indistintamente por confusiones del escribano o por el tipo de variante del mixteco. Detectaron los siguientes ejemplos, muy resumidos: 1) $t$ puede cambiar a $r$;2) $c$ puede cambiar a $q u, c u$; 3$) d z$ puede cambiar a s, ch, $x, z$; 4$) n$ puede cambiar a $\tilde{n}, u$; 5) $u$ puede cambiar a $v, o$; 6) hu puede cambiar a $v u$; 7) $q$ puede cambiar a $g$; 8) $y$ puede cambiar a $i, j ; 9) e$ puede cambiar a $i, c ; 10) h$ como saltillo ${ }^{46}$.

En la tabla 13 (pp. 86-89) podemos observar estas grafías utilizadas para escribir indistintamente los nombres de los días y detectar las siguientes variaciones gráficas de los días en el mixteco colonial:

- Para nombrar el día Lagarto encontramos cuatro formas gráficas mixtecas: quevi, quihui, qui, quihco ${ }^{47}$.

- Para el día Viento aparecen dos términos mixtecos debidos a la variación señalada por Arana y Swadesh del cambio de ch por $x$ en los nombres chi y $x i$. La primera forma gráfica es consistente en la mayoría de los códices analizados y la segunda sólo se encontró en el $\mathrm{Ma}$ pa de San Vicente el Palmar.

- Para el día Casa se presentan dos palabras distintas para nombrarlo. Aparecen indistintamente en un mismo documento, pero por lo general, se utiliza una forma gráfica o la otra. Los nombres en mixteco son $m a o^{48} \mathrm{y}$ cuau. La segunda palabra mixteca sí presenta muchas variaciones en la forma de registrarse, como quao, quaho, qoa. Estos cambios se deben a lo señalado por Arana y

46 Arana y Swadesh, 1965: 14-20. Estos autores encontraron que para el mixteco colonial los sonidos que correspondían a las grafías empleadas eran: para las vocales $/ \mathrm{a} /, / \mathrm{i} /, / \mathrm{o} /, / \mathrm{u} /$, /i herida/, esta última representada por la grafía $e$ en los documentos coloniales. Estas vocales también podían ser largas y nazalizadas. En cuanto a las consonantes, fueron: /t/, /k/,/s/, /nd/, /n/, /ñ /,/m/,/r/, /g/, /v/, /'/, /d/, /y/, principalmente. Cf. Arana y Swadesh (1965); para otra propuesta, véase Terraciano (1994).

${ }^{47}$ En el Códice Muro se registra el día Lagarto como queui (cf. Hermann, 2003). Este registro es una quinta variante del nombre.

${ }^{48}$ En el Códice Muro se registra el día Casa como mau (cf. Hermann, 2003). Este registro sería una variante de esta forma, en la que se escribe $u$ en lugar de $o$.
Swadesh sobre el uso de $c u, q u$ y $q$, y a la presencia de la $h$, que indica una aspiración o un saltillo. También vemos el cambio de la vocal $u$ por $o$.

- Para el día Lagartija, que aquí fue identificada con una iguana, los nombres encontrados son $q$, qhy. Las variaciones surgen en la forma de registrar $q h y$, que puede encontrarse como qh, qhi, ghy, que. En estos casos vemos los cambios de $q$ por $g$, el uso de $e$ por $i$, o bien $y$ por $i$.

- Para el día Serpiente el nombre de yo es consistente en todos los códices analizados.

- Para el día Muerte se encontraron dos términos para nombrarlo: mahu y cuahu. Una variación gráfica encontrada en la primera de estas palabras mixtecas es el intercambio de $u$ por $o$ en maho. La variante de cuahu sólo se ha registrado en el Lienzo de Santa María $\mathrm{Na}$ tivitas, en el que también disponemos de su correspondiente logograma. Las formas gráficas del día Muerte son muy semejantes a las de Casa; tal vez la distinción entre un día y otro sea por los tonos de la lengua mixteca, que no fueron registrados en el mixteco colonial. - Para el día Venado el nombre consistente fue quaa. En las Relaciones Geográficas aparece como cuaha, y en el Lienzo de Nativitas como cuaa. En los dos casos se ve el cambio del uso de $q u$ por $c u$, y en el primero también aparece la introducción de un saltillo indicado por la $h$. Otra variación encontrada fue guaa, registrada en el Códice Egerton, en la que vemos el cambio de $q$ por $g$, que, al parecer, era común en la variante del mixteco de la Mixteca Baja ${ }^{49}$.

- Para el día Conejo el nombre mixteco utilizado en todos los documentos es xayu, sayu o zayu. Lo único que resalta es el uso indistinto de las grafías $x, s$ y $z$.

- En el caso del día Agua, el único registro detectado fue en el Códice Egerton, con la palabra tuta y, por lo tanto, no pudo ser comparado ${ }^{50}$.

- Para el día Perro, las formas gráficas encontradas fueron ua y hua e ina. Los primeros dos términos se explican por los cambios de $u$ por $v$ y de $v$ por $h u$, de acuer-

\footnotetext{
${ }^{49}$ Cf. Arana y Swadesh, 1965.

${ }^{50}$ En el Códice Muro este nombre a aparece con los términos tucha y tuncha (cf. Hermann, 2003).
} 
do con Arana y Swadesh. Estos cambios explicarían también que en el Mapa de San Vicente el Palmar, en uno de los nombres de la genealogía inferior, en la cabeza 12 , se alcanza a leer la glosa $u v . .$, lo que nos indica que sería parte de la palabra utilizada para el día Perro, sólo que aquí los cambios obedecen a $u$ por $v$ y la $v$ por $u$ para dar $v u(a)$. También en este mismo mapa se detectó el término ina para Perro, el cual puede ser explicado ya sea como un uso del lenguaje normal y no del especial por parte del glosista, o bien que el término sea solamente $n a$, y que la $i$ forme parte del numeral que está perdido — de ser así, sería una evidencia más de un registro semejante en lenguaje especial encontrado en el del Códice Muro-.

- Para el día Mono, las formas gráficas encontradas son $\tilde{n} u u, \tilde{n} o o$ y ñoho. En este caso vemos que la $h$ está colocada para denotar el saltillo y los cambios de $u$ por $o$. Se debe señalar que en los códices de la Mixteca Baja son más frecuentes las formas de la palabra Mono con la vocal $o^{51}$.

- En el caso del día Hierba, el único registro se encuentra en el Lienzo de Nativitas con la forma cuañe, por lo que, al igual que el día de la novena posición, no es posible compararlo.

- Para el día Caña el nombre es consistente, aunque se encontraron las palabras huiyo, uiyo, viyo, en las que resaltan los cambios en las grafías de $h u$ por $u$ o por $v$.

- Para el día Jaguar el nombre es constante, bajo los términos vidçu, huiçu o huico, huiço, vico, en los que vemos el cambio señalado anteriormente de $h u$ por $v$, el intercambio de vocales $u$ por $o$ al final de la palabra y el uso de $c$ (que representa la $z$ ) o $c$.

- Para el día Águila, los nombres son sa o xa, en los que vemos el cambio de $s$ por $x$. En el Mapa de San Vicente el Palmar hay dos términos: qa o ca, que podrían ser el día Águila, si se confirma como posible el cambio de $s$ o $x$ por $q$ o c. Si no es así, entonces estas formas denotarían en este códice el día Lluvia con un cambio más probable de $o$ por $a$.

${ }^{51}$ En el Códice Muro se detectó el término ñua (cf. Hermann, 2003), que resulta otra variante de los nombres analizados en este estudio.
- Para el día Zopilote, la manera de escribir su nombre varía bastante: cuii, cuij, cuiy, cuy, quii y ccoiy. Pero a pesar de esta diversidad, notamos variaciones menores que se explican por los diferentes usos de $i$ por $y$ o $j$, así como el cambio de $u$ por $o$.

- Para el día Temblor, los términos utilizados son qhi o $q$ hy. Este registro sólo varía por el cambio de $i$ por $y$.

- Para el día Pedernal, las formas escritas encontradas son: cuxi, usi, qusi y coxi, en las que vemos los distintos usos de los escribanos de $c u$ por $q u, u$ por $o, x$ por $s$. La ausencia de una $c$ en una de las formas gráficas es más difícil de explicar. También resulta más conflictivo el registro de xico en lugar de coxi, encontrado en el Mapa de San Vicente el Palmar.

- Para el día Lluvia, las únicas formas gráficas registradas están en el Códice Egerton: co y go. Ya se dijo que el cambio de $c$ por $g$ es común en la variante del mixteco de la Mixteca Baja. Tal vez haya otro registro en el Mapa de San Vicente el Palmar con el término pa, que debía ser qa y en el que la $o$ se intercambió por $a$. Ésta puede ser otra evidencia, al igual que sucede en el Códice Muro, del registro en lengua mixteca para el día Lluvia.

- Finalmente, para el día Flor los registros son vaco o huaco, en los que vemos otra vez el intercambio de $h u$ por $v$.

c) Además, podemos reiterar que existe la utilización de varios términos para nombrar un mismo día en un mismo códice, como ocurre con los días de Lagarto, Casa, Muerte y Perro: quihui, qui; / mao, quao, qoa; / cuahu, mahu; / vua, na, respectivamente.

Las consideraciones anteriores (tabla 13, pp. 86-89) demuestran que los registros antroponímicos del Mapa de San Vicente el Palmar contribuyen al conocimiento de los nombres mixtecos de los días del calendario de 260 días, en especial para las posiciones $10^{\mathrm{a}}$ (Perro) y 19a (Lluvia). En el primer caso, encontramos en este códice el segundo registro que se tiene de este nombre y, en el segundo, sería el tercer registro conocido en el pequeño corpus de códices del noroeste de Oaxaca, que han sido clave para conocer los 20 nombres de la lista de los días 
mixtecos. Se puede añadir que, al respecto, queda pendiente para estudios futuros trabajar el significado de cada uno de los nombres de los días mixtecos para entender mejor la relación entre el ícono y el énfasis que le da la palabra mixteca correspondiente, así como la relación entre el lenguaje común y el lenguaje especial o sagrado.

\section{Bibliografía}

Acuña, René, 1984, Relaciones Geográficas del siglo XVI: Antequera, Instituto de Investigaciones Antropológicas, Universidad Nacional Autónoma de México, México.

—_, 1985, Relaciones Geográficas del siglo XVI: Tlaxcala, Instituto de Investigaciones Antropológicas, Universidad Nacional Autónoma de México, México.

Alcina, Franch José, 1993, Calendario y religión entre los zapotecos, Instituto de Investigaciones Históricas, Universidad Nacional Autónoma de México, México (Serie de Culturas Mesoamericanas, 3).

Alvarado, fray Francisco de, 1962 [1953], Vocabulario en lengua mixteca por los padres de la orden de predicadores, Instituto Nacional de Antropología e Historia, Secretaría de

Anders, Ferdinand, Maarten Jansen y Gabina Aurora Pérez Jiménez, 1994, "La gran familia de los reyes mixtecos", en Códices Egerton y Becker II, Fondo de Cultura Económica, Sociedad Estatal Quinto Centenario y Akademische Druck und Verlagsanstalt, México.

Arana, Evangelina y Mauricio Swadesh, 1965, Los elementos del mixteco antiguo, Instituto Nacional Indigenista, Instituto Nacional de Antropología e Historia, México.

__, 1961, "El lenguaje de los señores", Anales del Museo de Antropología, época 6a, t. XIII, Instituto Nacional de Antropología e Historia, México, pp. 217-230.

Brito Guadarrama, Baltazar, 2006, El Códice Guillermo Tovar de Huexotzingo. Análisis glífico y paleografia, tesis de maestría en estudios mesoamericanos, Facultad de Filosofía y Letras, Universidad Nacional Autónoma de México, México.

Caballero Morales, Gabriel, 2007, "El alfabeto y las palabras en la estructura gramatical de tu' un savi (idioma mixteco)", en Reina Ortiz Escamilla e Ignacio Ortiz Castro (eds.), Raíces mixtecas, Universidad Tecnológica de la Mixteca, Huajuapan de León, Oaxaca, pp. 243-285.

Caso, Alfonso, 1956, "El calendario mixteco", Historia Mexicana, vol. V, núm. 20, pp. 481-497.

—_, 1958, Mapa Xochitepec, Congreso Internacional de Americanistas, Copenhague.

1967, Los calendarios prehispánicos, Instituto de Investigaciones Históricas, Universidad Nacional Autónoma de México, México.

-, 1992 [1977], Reyes y reinos de la Mixteca, 2 ts., Fondo de Cultura Económica, México.

Códice Alfonso Caso (Colombino-Becker I), 1995, ed. facsimilar, Patronato Indígena, Instituto Nacional Indigenista, México.

Códice Becker II, 1994, ed. facsimilar, Fondo de Cultura Económica, Sociedad Estatal Quinto Centenario, Akademische Druck Und Verlagsanstalt, México.

Códice Bodley, 1960, ed. facsimilar, Sociedad Mexicana de Antropología, México.

Códice Borbónico, 1993, ed. facsimilar, Sociedad Estatal Quinto Centenario, Akademische Druckund Verlagsanstalt, Fondo de Cultura Económica, México.

Códice Borgia, 1993, ed. facsimilar, Sociedad Estatal Quinto Centenario, Akademische Druckund Verlagsanstalt, Fondo de Cultura Económica, México.

Códice Colombino, 1966, ed. facsimilar, Sociedad Mexicana de Antropología, México.

Códice Dehesa, 1892, antigüedades mexicanas publicadas por la Junta Colombina de México en el cuarto centenario de América, Oficina Tipográfica de la Secretaría de Fomento, láminas.

Códice Egerton, 1994, ed. facsimilar, Fondo de Cultura Económica, Sociedad Estatal Quinto Centenario, Akademische Druck Und Verlagsanstalt.

Códice Selden, 1964, ed. facsimilar, Sociedad Mexicana de Antropología, México.

Códice Sierra, 1982, ed. facsimilar de la edición de Nicolás León, Innovación, México.

Códice Telleriano Remensis, 1995, ed. facsimilar, en Eloise Quiñones Keber, Codex Telleriano Remesis. Ritual Divination and History in a Pictorial Aztec Manuscript, University of Texas Press, Austin.

Códice Tulane, 1991, ed. facsimilar, Akademische Druck U. Verlagsanstalt y Middle American Research Institute núm. 61, Universidad de Tulane, Nueva Orleans, Graz, Austria.

Códice Vaticano B, 1993, ed. facsimilar, Sociedad Estatal Quinto Centenario, Akademische Druckund Verlagsanstalt, Fondo de Cultura Económica, México.

Códice Vindobonensis, 1992, ed. facsimilar, Fondo de Cultura Económica, Sociedad Estatal Quinto Centenerio, Akademische Druck Und Verlagsanstalt, México.

Códice de Yanhuitlán, veáse la ficha de Jiménez Moreno y Salvador Higuera, 1940.

Códice Zacatepec, veáse la ficha de Smith, 1973a.

Códice Zouche Nuttall, 1992, ed. facsimilar, Fondo de Cultura Económica, Sociedad Estatal Quinto Centenario, Akademische Druck Und Verlagsanstalt, México. 
Córdova, fray Juan de, 1987, Arte del idioma zapoteco, Toledo, Instituto Nacional de Antropología e Historia, México.

Dahlgren, Barbro, 1990 [1954], La Mixteca: su cultura e historia prehispánicas, Universidad Nacional Autónoma de México, México.

Edmonson, Munro S., 1995, Sistemas calendáricos mesoamericanos. El libro del año solar, trad. de Pablo García Cisneros, Universidad Nacional Autónoma de México, México.

García, Gregorio, 1981, Origen de los indios del Nuevo Mundo e Indias Occidentales, ed. facsimilar, Biblioteca Americana, Fondo de Cultura Económica, México.

Gelg, Ignacio, 1987, Historia de la escritura, Alianza Editorial, Madrid.

Glass, John, 1975, "A Census of Native Middle American Pictorial Manuscripts", en colaboración con Donald Robertson, en Howard F. Cline (ed.), Guide to Ethnohistorical Sources, parte 3, Handbook of Middle American Indians, vol. 14, editor Robert Wauchope, University of Texas Press, Austin, pp. 81-280.

Gómez de Orozco, Federico, 1952, Mapa de Xochitepec: Interpretación de Federico Gómez de Orozco, Publicaciones Vargas Rea, México (Col. Amatlacuilot).

— 1955, Xochitepec, mapa pictográfico. Interpretación de Federico Gómez de Orozco, Biblioteca de Historiadores Mexicanos, Vargas Rea, México.

Hermann Lejarazu, Manuel, 2003, Códice Muro. Un documento mixteco colonial, Gobierno Constitucional del Estado de Oaxaca, Secretaría de Asuntos Indígenas, Consejo Nacional para la Cultura y las Artes, Instituto Nacional de Antropología e Historia, México.

Historia de los mexicanos por sus pinturas, 2003, ed. de Joaquín García Icazbalceta, en Anales del Museo Nacional de México. Breve Antología Facsimilar, suplemento especial del Boletín Oficial del Instituto Nacional de Antropología e Historia, Casas Benigno (ed.), México, pp. 27-48.

Jansen, Maarten, 1985, "Las lenguas divinas del México precolonial”, Boletín de Estudios Latinoamericanos y del Caribe, núm. 47, pp. 65-87.

Jiménez Moreno, Wigberto y Salvador M. Higuera, 1940, Códice Yanhuitlán, Museo Nacional, México.

Köning, Viola, 1979, Inhaltliche Analyse und Interpretation von Codex Egerton, Beiträge zur mittelamerikanischen Völkerkunde XV, Hamburgo.

Landa, Diego de, 1986, Relación de la cosas de Yucatán, introd. de Angel María Garibay, Miguel Ángel Porrúa, México (Biblioteca Miguel Ángel Porrúa, 13).

León Romero, Julieta, 2004, Urdiendo significados: técnicas, diseños y mitos en textiles de Santiago Jamiltepec, Oaxaca. Tradición oral y organizaciones de mujeres tejedoras y bor- dadoras mixtecas, tesis de licenciatura en etnohistoria, Escuela Nacional de Antropología e Historia, Secretaría de Educación Pública, México

León, Nicolás, 1982, Códice Sierra. Traducción al español de su texto en náhuatl y explicación de sus pinturas jeroglíficas, Innovación, México.

Lienzo de Santa María Nativitas, 2001, foto facsimilar en Relaciones. Estudios de Historia y Sociedad, núm. 86, vol. XXII, primavera, El Colegio de Michoacán.

Reyes, fray Antonio de los, 1976 [1593], Arte en lengua mixteca, De Charencey, Casa Pedro Balli, México (Publications in Anthropology, num. 14) edición facsimilar de Vanderbilt University, Nashville, Tennessee

Robertson, Donald, 1959, Mexican Manuscript Painting of the Early Colonial Period, Yale University Press, New Haven.

Rodríguez Cano, Laura, 1996, El sistema de escritura ñuiñe: análisis del corpus de piedras grabadas de la zona de la "Cañada” en la Mixteca Baja, Oaxaca, tesis de licenciatura en arqueología, Escuela Nacional de Antropología e Historia, Secretaría de Educación Pública, México.

-, 1999, "El calendario de 260 días en las inscripciones ñuiñes”, Cuadernos del Sur, año 5, núm. 14, mayo, Instituto Nacional de Antropología e Historia-Centro Oaxaca, Centro de Investigaciones y Estudios Superiores en Antropología Social-Istmo, Instituto de Investigaciones Sociales de la Universidad Autónoma Benito Juárez de Oaxaca, Instituto Welte, Instituto Tecnológico de Oaxaca, Oaxaca, pp. 15-34.

__, 2001, "Los registros del tiempo en el México prehispánico”, fascículo núm. 56, en Lorenzo Ochoa (coord.), Gran historia gráfica de México ilustrada. T. I: El mundo prehispánico. De la prehistoria a la llegada de los españoles, Planeta, De Agostini, Consejo Nacional para la Cultura y las Artes, Instituto Nacional de Antropología e Historia, pp. 301-320.

_ 2005, "Los registros de los 20 días en las inscripciones de Xochicalco", en Socorro Pimentel Pereda (coord.), X Jornadas de Etnohistorias. Homenaje al Dr. Joaquín Galarza: 31 años haciendo etnohistoria, memorias en disco compacto, Escuela Nacional de Antropología e Historia, México.

—_ en preparación, Los topónimos de la Mixteca Baja. Análisis de sus componentes en piedra, mapas, lienzos y códices, tesis de doctorado en estudios mesoamericanos, Facultad de Filosofía e Historia, Universidad Nacional Autónoma de México, México.

Sahagún, Bernardino, 1979, Códice Florentino, 3 vols., edición facsimilar del original de la Biblioteca de Médicis, Archivo General de la Nación, Gobierno de la Ciudad de México, México. 
, 2000, Historia general de las cosas de Nueva España, 3 ts., ed. de Josefina García Quintana y Alfredo López Austin, Secretaría de Educación Pública, Consejo Nacional para la Cultura y las Artes, México (Col. Cien de México).

Smith, Mary Elizabeth, 1973a, Picture Writing from Ancient Southern Mexico: Mixtec Place Signs and Maps, University of Oklahoma Press, Norman, Oklahoma.

__ 1973b, "The Relationship between Mixtec Manuscript Painting and the Mixtec Language: A Study of Some Personal Names in Codices Muro and Sanchez Solis", en Elizabeth P. Benson (ed.), Mesoamerican Writing Systems, Dumbarton Oaks, Washington, pp. 47-98.

— 1979 , "Codex Becker II: A Manuscript from the Mixteca Baja?”, Archiv für Völkerkunde, núm. 33, pp. 29-43.

— y Ross Parmenter, 1991, The Codex Tulane, Akademische Druck U. Verlagsanstalt Graz Austria, Middle American Research Institute núm. 61, Universidad de Tulane, Nueva Orleans.

Tedlock, Barbara, 1993, Time and the Higland Maya, 2a ed. revisada, University of New Mexico Press, Albuquerque

Terraciano, Kevin, 1994, Nudzahui History: Mixtec Writing and Culture in Colonial Oaxaca, tesis doctoral, University of California.

Thompson, J. Eric S., 1950, Maya Hieroglyphic Writing, Carnegie Institution of Washington, Washington, (Publication, 589).

Urcid Serrano, Javier, 1992, Zapotec Hieroglyphic Writing, tesis doctoral, Department of Anthropology, Yale University, New Haven.

_-, 2001, Zapotec Hieroglyphic Writing Studies in Precolumbian, Dumbarton Oaks, Washington (Art and Archaeology, 34).

Van Doesburg, Sebastián, 2001, "De linderos y lugares: territorio y asentamiento en el Lienzo de Santa María Nativitas", en Relaciones. Estudios de Historia y Sociedad, vol. XXII, núm. 86, primavera, El Colegio de Michoacán.

Weitlaner, Roberto, Gabriel de Cicco y Donald Brockington, 1998, "Un calendario de los zapotecas del Sur", en Manuel Ríos (comp.), Los zapotecas de la Sierra de Oa$x a c a$, Instituto Oaxaqueño de las Culturas, Fondo Estatal para la Cultura y las Artes, Centro de Investigaciones y Estudios Superiores en Antropología Social, México.

\section{Fuentes no publicadas}

Códice Mixteco Postcortesiano núm. 36, s.f., fotografía a tamaño natural en el Museo Regional de Huajuapan de León, Oaxaca.

Lienzo de Nativitas, s.f., fotografía facsímil donada por la Biblioteca Burgoa a Santa María Nativitas.

,- 2005 , fotografías del original tomadas en el trabajo de campo en agosto 2005 dentro del proyecto de investigación formativa "Cosmovisión, escritura e imagen de Mesoamérica”, coordinado por Laura Rodríguez Cano en la Escuela Nacional de Antropología e Historia, México.

, 2005, Registro gráfico 1:1 realizado en el trabajo de campo en agosto 2005 dentro del proyecto de investigación formativa "Cosmovisión, escritura e imagen de Mesoamérica”, coordinado por Laura Rodríguez Cano en la Escuela Nacional de Antropología e Historia, México.

Mapa de San Vicente el Palmar, 1960, copia de un lienzo del siglo XVI, Lienzo 57 glosas, Archivo del Registro Agrario Nacional de Oaxaca.

_, $2004-2005$, fotografías del mapa orginal tomadas en San Vicente durante el trabajo de campo del proyecto "Geografía histórica de la Mixteca Baja. Toponimia y espacio políticos del siglo VIII al XVI", a cargo de Laura Rodríguez Cano en la Escuela Nacional de Antropología e Historia, México.

__, 2007, registro gráfico escala 1:1 del Mapa de San Vicente el Palmar dentro del proyecto "Geografía histórica de la Mixteca Baja. Toponimia y espacio políticos del siglo VIII al XVI", a cargo de Laura Rodríguez Cano en la Escuela Nacional de Antropología e Historia, México.

Mapa de Xochitepec, 2001, fotografías del Museo Nacional de Copenaghe, Dinamarca.

, 2000, copia del Mapa Xochitepec en la Mapoteca de la Subdirección de Documentación de la Biblioteca Nacional de Antropología e Historia. 